\title{
Differential compartmentalization of BMP4/NOGGIN requires NOGGIN trans-epithelial transport
}

\author{
Tien Phan-Everson ${ }^{1-2+}$, Fred Etoc $^{1+}$, Ali H. Brivanlou ${ }^{1 *}$, Eric D. Siggia ${ }^{2 *}$ \\ ${ }^{1}$ Laboratory of Stem Cell Biology and Molecular Embryology, The Rockefeller University, New \\ York, New York 10065, USA. \\ ${ }^{2}$ Laboratory of Physical, Mathematical, and Computational Biology, The Rockefeller University, New \\ York, New York 10065, USA. \\ + Co-first Authors \\ * Joint Corresponding Authors \\ Correspondence: brvnlou@rockefeller.edu; siggiae@mail.rockefeller.edu
}

\section{Summary}

Using self-organizing human models of gastrulation, we previously showed that (i) BMP4 initiates the cascade of events leading to gastrulation; (ii) BMP4 signal-reception is restricted to the basolateral domain; and (iii) in a human-specific manner, BMP4 directly induces the expression of NOGGIN. Here, we report the surprising discovery that in human epiblasts, NOGGIN and BMP4 were secreted into opposite extracellular spaces. Interestingly, apically-presented NOGGIN could inhibit basally-delivered BMP4. Apically-imposed microfluidic flow demonstrated that NOGGIN traveled in the apical extracellular space. Our co-localization analysis detailed the endocytotic route that trafficked NOGGIN from the apical space to the basolateral intercellular space where BMP4 receptors were located. This apical-to-basal transcytosis was indispensable for NOGGIN inhibition. Taken together, the segregation of activator/inhibitor into distinct extracellular spaces challenges classical views of morphogen movement. We propose that the transport of morphogen inhibitors regulates the spatial availability of morphogens during embryogenesis.

\section{Keywords}

human, embryonic stem cells, epiblast, polarity, morphogen, BMP4, NOGGIN, SMAD signaling, transcytosis, endocytosis 


\section{Introduction}

Understanding the mechanisms that give rise to spatial patterns in development is a challenge that has intrigued scientists for over a century (Crick, 1970; Morgan, 1901; Stumpf, 1966). One classical mechanism involves morphogens: long-range signaling molecules that control cell fate specification in a concentration-dependent manner. As such, morphogen gradients act as positional cues that direct the patterning of developing tissues during embryogenesis (Rogers and Schier, 2011; Warmflash et al., 2012). It is therefore critical for morphogenetic cues to be correctly modulated, positioned, and interpreted by the target tissues.

It is often implicitly assumed that morphogens and their secreted inhibitors can freely spread from a source to their point of action. Morphogen spreading is frequently conceptualized and modeled as simple diffusion with decay, though the actual molecular mechanisms are likely to be much more complicated and highly dynamic (Hidalgo, 2019; Kornberg, 2017; Muller et al., 2013; Sorre et al., 2014). Moreover, how morphogen signaling integrates within cellular compartments is mostly unknown; the extracellular micro-environment that contains these diffusive molecules is often ignored. While model organisms have been instrumental in the dissection of long-range morphogen signaling in early development, the early human embryos have a geometry different from most other model organisms. (Muller et al., 2013; Rogers and Schier, 2011; Wartlick et al., 2014; Wartlick et al., 2009; Zhang et al., 2019). The distinct epithelialized epiblast morphology inherent to the human bilaminar embryonic disc adds yet another layer of complexity (O'Rahilly and Muller, 2010). Epithelial tissues, which play key roles in shaping human's basic embryonic body plan, consist of a laterally cohesive sheet of cells whose epithelial integrity is maintained by adherens and tight junctions, hence presenting a diffusion barrier (Gilmour et al., 2017). Another defining characteristic of epithelia is a distinct apicobasal polarity which enables apical and basolateral domains to adopt distinct features. As such, signaling is coupled to global embryo as well as local tissue geometry. Although a number of morphogens responsible for embryonic patterning have been identified, we are very far from a quantitative understanding of the dynamics of signaling by these morphogens, which are collectively responsible for transforming a zygote into an embryo.

BMP4 is among the early embryonic morphogens that play critical roles in the patterning of the epiblast (Arnold and Robertson, 2009). We have previously shown that BMP4 alone is sufficient to initiate germ layer self-organization in a gastrulation-like process either in flat 2D micropatterned epiblast model (Etoc et al., 2016), or in a 3D model for primitive streak formation and anteriorposterior symmetry-breaking (Simunovic et al., 2019). Strikingly, our in-vitro models have revealed that BMP4 reception in the polarized epithelium is restricted to the basolateral cell domain, due to BMP receptors' basolateral localization below diffusion barrier - the tight junctions (Etoc et al., 2016; Nallet-Staub et al., 2015; Zhang et al., 2019).

In contrast to the detailed characterization of morphogens' signaling pathways, the movement of the morphogens' inhibitors has received less attention. NOGGIN - a BMP4 inhibitor - is the first molecule reported to have the properties of a Spemann organizer, inducing dorsal structures (Smith and Harland, 1992). It is well-established that NOGGIN antagonizes BMP4 by binding tightly to BMP4, preventing binding to BMP receptors (Zimmerman et al., 1996). As a human-specific trait, BMP4 induces the direct expression of its own inhibitor NOGGIN, which is required for germlayer patterning in human models of gastrulation (Etoc et al., 2016). The mechanism for NOGGIN spreading and its associated kinetics in embryonic tissue have not been investigated. 
In this article, we interrogate the interplay of the morphogen/inhibitor pair BMP4/NOGGIN within of model for the polarized human embryonic disc. Unexpectedly, we found that BMP4 and NOGGIN were selectively secreted into opposite sides of the polarized epithelium, effectively segregating the ligand and its inhibitor into distinct extracellular spaces. Moreover, utilizing a microfluidic flow chamber, we unambiguously demonstrated the long-distance diffusion of NOGGIN through the extracellular medium at the apical side, and the short-distance diffusion of BMP4 over few direct neighbors. This discovery challenges current dogma which assumes that the morphogen activator and inhibitor diffuse in the same compartment. Surprisingly, we further demonstrate that apically-applied NOGGIN can inhibit basally-applied BMP4 across a tight hESC epithelium, which points to mechanisms of trans-epithelial transport. And finally, we trace the transcytosis route of apical NOGGIN through the endosomal system. Overall, we highlight a complex mechanism where NOGGIN is apically secreted, diffuse over long distance in the apical compartment, internalized by receiving cells, transcytosed, and trafficked to the basal-lateral surface close to the subcellular locus where BMP receptors are localized. Our study shed light on an important and unexpected level of regulation for the transport of morphogen inhibitors whose role in spatially restricting the spread of morphogen signaling ultimately shapes the embryonic body plan.

\section{RESULTS}

\section{BMP4 is Secreted Basally and Spreads Locally}

Under culture conditions designed for pluripotency maintenance, confluent hESCs form an apicobasal polarized epithelium reminiscent of the organization of the embryonic epiblast with tight junctions separating the apical and the baso-lateral cell membranes (Supp Fig 1A). As previously shown, hESCs localize their BMP receptors to the basolateral domain just below the tight junctions, making them non-responsive to apically applied BMP4 (Fig 1A) (Etoc et al., 2016). In order to study the signaling dynamics of BMP4 within our model epiblast, we used our own hESC line, RUES2 (NIH\# 00012), to stably express transgenes for doxycycline (DOX)-dependent induction of epitope-tagged BMP4 (Fig 1B). BMP4-secreting cells were also transfected with a constitutively expressed nuclear marker, H2B-mCitrine, to allow tracing (Fig 1B). Since secretion can potentially take place from both sides of the polarized epithelium, we cultured the cells on transwell filters, allowing easy access to both apical and basal compartments. At a starting seeding density of $\sim 4,000$ cells $/ \mathrm{mm}^{2}$; the cells form a confluent, polarized epithelium on the filters after $22 \mathrm{hrs}$ in culture (Supp Fig 1A). This defines our set of standard conditions for the culture of our model epiblasts.

We used DOX to induce RUES2 on transwell filters to produce BMP4 then probed for secreted BMP4 in the apical and basal compartments. BMP4 was found nearly exclusively in the basal media for up to $24 \mathrm{hrs}$ (Fig 1C). We then characterized BMP4 lateral spreading dynamics by mixing a low proportion (1:200) of BMP4-producing hESCs within a W'T hESCs background. This allowed us to quantify the spatial range of BMP4 propagation in the WT "receiving" cells by quantifying nuclear phosphorylated SMAD1/5. Starting at 8 hrs post-induction, basally-secreted BMP4 activated nuclear pSMAD1 $/ 5 / 8$, first in an autocrine manner in the secreting cells. At later time-points, a paracrine signal - which could be fitted by a single exponential decay - spread through the epithelium and reached a characteristic length of $20 \mu \mathrm{m}$ from the closest secreting cells after 24 hrs (Fig 1D, 1E).

\section{NOGGIN is Secreted Apically and Forms a Concentration Gradient}


Since NOGGIN is expressed as a response to BMP4 (Etoc et al., 2016), we then asked whether NOGGIN propagated with the same characteristics as BMP4, i.e. basal secretion with short-ranged lateral propagation. Similar to the strategy we employed for studying BMP4 propagation, we generated an RUES2 line stably incorporating a transgene for doxycycline-dependent induction of epitope-tagged NOGGIN together with a constitutively expressed H2B-mCherry nuclear marker (Fig 2A). Compared to BMP4, in our induction assay on transwells, secreted NOGGIN could be detected at earlier time points. To our surprise, we found that V5-tagged NOGGIN was exclusively secreted to the apical media after 2-, 4- and 8-hr induction (Fig 2B). As such, the ligand BMP4 and its inhibitor NOGGIN were secreted into opposite extracellular spaces.

We next examined the dynamics of NOGGIN transport within our model epiblast by seeding a low dilution of NOGGIN-producing cells in a background of WT-RUES2. We applied DOX for different durations to induce secretion of NOGGIN, followed by a brief $1 \mathrm{hr}$ pulse of BMP4 presented to the basal media. Spatial domains of BMP4 activity were highlighted by pSMAD1/5/8 staining. As expected, NOGGIN-overexpressing cells effectively prevented BMP4-dependent initiation of pSMAD1/5/8 autonomously and non-autonomously. The spatiotemporal range of NOGGIN inhibition was defined by the area of pSMAD1/5/8-negative RUES2 surrounding the NOGGIN-producing cells (Fig 2C). At corresponding times, the range of inhibition extended from $13 \mu \mathrm{m}$ at $4 \mathrm{hrs}$, to $150 \mu \mathrm{m}$ at $24 \mathrm{hrs}$ (Fig 2D).

Finally, we probed the concentration profile of NOGGIN away from a secreting source. We induced diluted NOGGIN-expressing cells for a defined period of time (6 hrs) and then challenged the tissue globally by application of different concentrations of BMP4 from the basal compartment. As expected, NOGGIN's efficiency in counteracting pSMAD1/5/8 induced by basally-applied BMP4 was inversely proportional to BMP4 concentration: the inhibition rings around the NOGGIN-producing cells had decreasing radii as BMP4 concentration increased (Fig 2E, 2F). This demonstrates that the activity of NOGGIN away from a source was indeed graded.

\section{Apically-Applied NOGGIN Can Inhibit Basally-Applied BMP4}

That BMP4 and NOGGIN are secreted into different extracellular spaces is surprising since NOGGIN has to directly bind BMP4 in order to prevent its interaction with BMP receptors and block signaling. Where and how can two proteins, in different compartments separated by a diffusion barrier - the tight junctions, meet and interact? In order to address this question, we first set up a series of time-course Western blot analysis of the cell lysates for pSMAD $1 / 5 / 8$ activation under different signaling conditions. As expected, a sustained basal application of BMP4 resulted in sustained pSMAD $1 / 5 / 8$ response in the layer, while a single short pulse of BMP4 generated a response for $3 \mathrm{hrs}$ (Fig 3A). However, and most strikingly, addition of NOGGIN in the apical compartment completely shut down ongoing BMP4 signaling within 2 hours of application. The dynamics of NOGGIN inhibition occurred slower as compared to when the pathway is challenged by the small compound inhibitor LDN, and yet faster than when BMP4 was removed from the basal side (Fig 3A). Thus NOGGIN trafficking from apical to basal occurs within a 2-hr window. Moreover, NOGGIN's inhibitory effect was maintained for up to $3 \mathrm{hrs}$ after NOGGIN washout (Supp Fig 1B), suggesting that cells retain a short-term memory of their exposure to NOGGIN.

To control independently for physiological morphogen levels and kinetics, we tested the efficacy of NOGGIN inhibition in a context of BMP4 expressing cells. BMP4-producing cells, diluted in a background of WT-RUES2, were induced to secret the ligand. The epithelium was then challenged with various concentrations of recombinant NOGGIN, applied apically or basally. While basally- 
applied NOGGIN was most effective at inhibiting BMP4 signaling, apically-applied NOGGIN was also capable of switching off sustained BMP4 signaling in a dose-dependent manner (Fig 3B, 3C). Analysis by Western blot confirms that apical NOGGIN rapidly quenches the response to a preceding pulse of BMP4 (Supp Fig 1C).

Overall, these experiments demonstrate that apically-applied NOGGIN functionally and efficiently inhibits basal BMP4, and with similar kinetics as basal BMP4 washout. Moreover, cells maintain a memory to NOGGIN exposure, which points towards mechanisms of internalization and trafficking of NOGGIN from the apical to basal compartment where BMP4 is present.

\section{NOGGIN Diffuses Across the Apical Compartment}

We hypothesized that diffusion in the extracellular medium at the apical side was a major mechanism for NOGGIN's long-range propagation in the epithelium. To test this, we customized a glass-bottomed microfluidic culture platform which supported controlled perfusion flow rates, and applied apical laminar flow (Material and Methods, Supp Fig 2A, 2B, 2C). This microfluidic system supported the epithelialization of hESCs while maintaining their pluripotency at both low and high flow rates (Supp Fig 3A, 3B). This occurred regardless of the surface in which the cells were cultured as both glass and filter substrates led to similar signaling range and spreading dynamics (Supp Fig 3C, 3D and Fig 1D). We utilized this microfluidic device to validate our hypothesis by demonstrating that briefly switching a flow of $10 \mu \mathrm{l} / \mathrm{hr}$ to a high flow rate of $1000 \mu \mathrm{l} / \mathrm{hr}$ washed away secreted NOGGIN at the apical side and lessen or eliminate its inhibition. Since we have demonstrated earlier that BMP4 was basally secreted, application of an apical flow should not perturb its local spreading. As a control, we diluted BMP4 secreting cells into the W'T-RUES2 epithelium at a ratio of 1:200, which allowed us to quantify the spread of pSMAD $1 / 5 / 8$ activity around isolated BMP4 sources (Fig 4A, 4B). No difference in the BMP4 signaling ranges between low and high flow regimes after 6 hrs of doxycycline induction was detected, except for an increase in the amplitude of pSMAD1/5/8 intensity, in the high flow condition, consistent with a washout of other endogenous inhibitors induced by BMP4 stimulation (Etoc et al., 2016). This minimal effect of flow on BMP4 lateral spreading is consistent with the basal secretion of BMP4 and its presumed uptake in nearby cells.

Increasing the ratio of BMP4-secreting cells in W'T-RUES2 to 1:10 led to uniform expression of pSMAD1/5/8, which was uniformly inhibited at low flow rate after 6 hrs of DOX (Fig 4D) when a small number of NOGGIN-secreting cells (1:500) were added, (Fig 4C and 4D). In contrast, high apical flow showed active BMP4 signaling only in cells a distance away from NOGGIN-secreting cells (Fig 4D). Thus, high apical flow reduced NOGGIN inhibition spread consistent with its apical secretion and activity when apically supplied. The persistence of BMP4 inhibition specifically around the NOGGIN-secreting cells in the high flow condition argues that the flow was neither generically activating BMP4 signaling by another route such as shear stress, nor washing out some unknown inhibitor. Moreover, the shear rate on the cells at the highest flow is 0.03 dynes $/ \mathrm{cm}^{2}$ which is 30 times less than the lowest value that elicits a response in endothelial cells (Ballermann et al., 1998). The simplest explanation of our data is thus that the flow washed away NOGGIN and precluded its transport to the cells furthest from the NOGGIN secreting cells. Overall, these experiments concur that NOGGIN traveled in the apical extracellular space while BMP4 used the basolateral space.

\section{NOGGIN's Subcellular Localization}

To further examine how apically-spreading NOGGIN protein traffics intracellularly to inhibit BMP4, we mixed a small number of NOGGIN-secreting with WT-RUES2 (1:100) and assessed the 
subcellular localization of NOGGIN throughout the layer by staining the V5 tag after 8 hrs of induction followed by $1 \mathrm{hr}$ of basal BMP4 application (Fig 5A). As expected for secreting cells, high concentration of NOGGIN was found in the golgi (Supp Fig 3E). pSMAD1/5/8 expression delineated the range of NOGGIN activity in surround cells. Unexpectedly, however, in receiving cells, NOGGIN was mostly found at the basolateral domain (Fig 5A). Quantification of NOGGIN localization in the $\mathrm{X} Z$ plane indicated that NOGGIN consistently localized below tight junctions as demarcated by ZO-1 labeling (Fig 5B). This NOGGIN lateral accumulation tightly overlapped with the expression patterns of BMPR1a and BMPR2 (Fig 5C, 5D). In addition to labeling the basolateral domain, NOGGIN immunostaining also appeared as discrete puncta of various sizes, dispersed in the cytoplasm, indicative of endocytic vesicles in the apical pole of the cells, both at and below the level of tight junction marker ZO-1 (Fig. 5C, 5E). Taken together, our results suggest that following apical secretion from the source, NOGGIN enters receiving cells on the apical side, traffics through endocytotic vesicular compartments, and ultimately reaches the basolateral side near BMP receptors.

\section{NOGGIN Trans-Epithelial Transport}

We suspected that trafficking of NOGGIN was a prerequisite for its effect on pSMAD1/5/8 levels. Taking advantage of the physical properties of the plasma membrane, lowering the temperature of the cell culture is a commonly used method for nonspecific inhibition of endocytosis (Brunner et al., 2020). WT-RUES2 were first basally stimulated with BMP4, then NOGGIN was added apically or basally either at $37^{\circ} \mathrm{C}$ or at $4^{\circ} \mathrm{C}$. At $4^{\circ} \mathrm{C}$, the inhibitory effect NOGGIN has on pSMAD $1 / 5 / 8$ was eliminated, regardless of whether NOGGIN was added apically or basally (Fig 6A). This result suggests that the trafficking of NOGGIN is crucial for its modulatory effect on BMP4 signaling.

We then hypothesized that NOGGIN was endocytosed specifically via clathrin-dependent endocytosis, similar to BMP2 and BMPR (Hartung et al., 2006; Paarmann et al., 2016). In order to probe NOGGIN endocytosis, we took advantage of the small molecule Dyngo4a which inhibits dynamin - an essential regulator for the internalization of endocytotic vesicles via clathrin-mediated endocytosis and micropinocytosis (McCluskey et al., 2013). When recombinant NOGGIN was presented to the apical or basal compartment, the protein was internalized as demonstrated by Western Blot on the cell lysate. Only apical internalization was effectively blocked by Dyngo4a concurrent treatment, demonstrating the specific requirement for dynamin in apical NOGGIN uptake (Fig 6B). On the other hand, Dyngo4a pre-treatment did not affect BMP4 signaling (Supp Fig 4A).

We next tested whether NOGGIN underwent apical to basal transcytosis. To this end, we collected V5-tagged-NOGGIN-conditioned media from the apical culture media of NOGGIN-secreting cells. This conditioned media was applied to the apical compartment atop polarized hESC epithelium for up to $48 \mathrm{hrs}$. Consistent with transcytosis, V5-tagged-NOGGIN was recovered in the opposite side of the filter, in the basal compartment starting at $36 \mathrm{hrs}$ after application (Fig 6C). Following the experiment, immunofluorescence and permeability assays were performed on the same hESC samples to confirm epithelial barrier integrity (Supp Fig 4B, 4C, 4D). This demonstration of NOGGIN transcytosis explains the detection of NOGGIN in the basal media at $24 \mathrm{hrs}$ in the NOGGIN secretion experiment (Fig 2B). The difference in timeline for NOGGIN basal detection in the two experiments can be explained by the difference between continuous NOGGIN production in the secretion experiment and gradual NOGGIN degradation within the conditioned media in the transcytosis experiment. Together, these results again support the hypothesis that NOGGIN undergoes apical-basal transcytosis. 
Next, to dissect the endocytotic pathway associated with NOGGIN transport, we carried out a series of co-localization analyses of NOGGIN and various endosomal markers. The presence of NOGGIN in specific endosomal compartments: pinocytotic vesicles, apical sorting endosomes (ASE), early endosomes (EE), apical recycling endosomes (ARE), common recycling endosomes (CRE), and basal sorting endosomes (BSE) was measured by quantitative immunofluorescence colocalization (Brown et al., 2000; Cresawn et al., 2007; Knight et al., 1995; Lapierre et al., 2012; Li et al., 2015; Odorizzi et al., 1996; Perez Bay et al., 2016; Sheff et al., 1999; Simonsen et al., 1998). NOGGIN-producing cells diluted in a WT hESC epithelium (1:100) were induced to secrete NOGGIN for $24 \mathrm{hrs}$. Paired immunostaining of V5 and multiple endosomal markers was then performed in receiving cells, followed by co-localization analysis. Confocal microscopy was able to resolve domain-selective labeling of markers for pinocytotic vesicles, ASE, and ARE: pinocytotic vesicles and ASE were found exclusively in the apical region while the majority of ARE was found in the supranuclear region (Fig 6D). NOGGIN profile (Supp Fig 5A) and endosome profile along the baso-lateral axis was assessed relative to the tight junction marker ZO-1 (Supp Fig 5B) (for summary of endosomal markers, see Fig 6E; for full protocol description, see Methods). Colocalization profile (Supp Fig 5C) indicates that most of the co-localization between NOGGIN-V5 and endosomal markers occurred at the level of or below tight junctions. The fraction of NOGGIN-V5 that co-localized with each endosomal marker was graphed against the fluorescence profile of the respective endosome (Fig 6E). V5 labeling was found to localize with markers for pinocytotic vesicles (labeled by Dextran-10'), ASE (labeled by WGA-10'), EE (labeled by early endosome antigen 1 EEA1), CRE (labeled by Transferrin-45'), and BSE (labeled by Transferrin-5'). Co-localization was not observed between V5 and ARE (labeled by Rab11a). To verify that the colocalization fraction represented valid, meaningful localization, the fraction of endosomal markers that co-localized with NOGGIN was graphed against the fluorescence profile of the respective endosome (Supp Fig 5D). Thus these results suggest that NOGGIN upon endocytosis by pinocytotic vesicles, travels through $\mathrm{EE}$ and $\mathrm{ASE}$, before arriving at the CRE. From the CRE, NOGGIN is directed to the BSE and finally targeted for exocytosis to the inter-cellular space where BMP receptors are localized through the basolateral membrane (Fig 7).

\section{Discussion}

The surprising observation that in human model epiblast, a pair of secreted morphogen and inhibitor that directly bind each other are in fact initially secreted into opposite extracellular spaces forces a reconsideration of our current understanding of the molecular mechanisms underlying embryonic pattern formation. That BMP4 is secreted baso-laterally is consistent with the localization of the BMP receptors (Etoc et al., 2016). NOGGIN apical secretion into an opposite compartment separate from BMP4, which was not anticipated by current models, might represent a necessary mechanism as it would prevent immediate binding and inactivation of both factors and enable their patterning roles over large distances.

The spread of BMP4 and NOGGIN activity from a localized source was consistent with Turing's reaction-diffusion model, which postulates that the inhibitor must travels faster than ligand. The spread of NOGGIN was long-ranged, and almost 8 times greater than the lateral spread of BMP4 which remained restricted to only 2-3 adjacent cell neighbors. The differential diffusion rates may be regulated by the extracellular matrix as NOGGIN and BMP4 bind components of the extracellular matrix with different affinities (Ohkawara et al., 2002; Paine-Saunders et al., 2002; Rider and Mulloy, 2017). Additionally, the biophysical and geometrical properties of the apical and basal extracellular 
compartments differ. Therefore, the possibility that secreted molecules generally diffuse further at the apical side than at the basal side cannot be excluded. This situation has been shown to be the case in the luminal cavity of the implanting mammalian embryo, where the amniotic cavity on the apical side of the epithelia allows for the rapid transport of secreted factors, potentially to concentrate and homogenize inhibition through all cells lining the lumen (Simunovic et al., 2019; Zhang et al., 2019).

One caveat of our experimental design is that in the absence of detection methods to visualize endogenous signals, we had to rely on over-expression systems which produce protein levels higher than those found in vivo. However, time- and concentration-response curves show smooth variations, and our results for exogenously applied BMP4 or NOGGIN are consistent with those from the DOX induced cell lines. Thus, cells at a distance from the source do experience a graded concentration profile. These cells at the boundary between those that do and do not respond to pSMAD1/5/8 encounter relevant concentrations of morphogen/inhibitors. Therefore, given the limitation of current technologies, we believe the cellular responses occurring at the boundary are indicative of what happens in vivo.

The polarized secretion of NOGGIN and BMP4 exemplifies how an epithelium can create a sharp boundary within an embryo. Cells on the apical side would have BMP inhibited while those on the basal side would experience BMP signaling. This phenomena was recently proposed in connection with WNT signaling in the developing epidermis where a single multipotent progenitor epithelium defines the boundary between WNT activity on its basal side and WNT repression on its apical side (Matos et al., 2020). Moreover, it becomes increasingly clear that during gastrulation, while important signals are supplied by the visceral endoderm or hypoblast, signal reception is controlled by epithelial cell polarity (Etoc et al., 2016; Zhang et al., 2019). How epithelial cell types integrate morphogen signals will have to be incorporated in models of epiblast symmetry breaking to understand communication between embryonic and extra-embryonic populations.

Epithelial polarity also operates to control vesicular trafficking machineries and regulates vectorial transport (Rodriguez-Boulan et al., 2005; Rodriguez-Boulan and Macara, 2014). We have traced the path of NOGGIN from the early sorting endosomes on the apical side to the basal sorting endosomes and final localization next to the BMP receptors. The baso-lateral targeting of NOGGIN makes sense as it might be more efficient for an inhibitor to shield a small pool of very localized receptors than a diluted batch of ligand distributed through the more extended extracellular space. However, while we have shown that NOGGIN can undergo transcytosis and neutralize BMP4 on the baso-lateral surface, it remains unclear whether NOGGIN directly enters the same pool within endosomal compartments, or if BMP4 is constitutively degraded after endocytosis (Hartung et al., 2006; Paarmann et al., 2016). Our study therefore does not eliminate the possibility that BMP4 and NOGGIN meet inside of transport vesicles.

We showed previously that ACTIVIN/NODAL receptors are also basolaterally localized in human gastruloids grown in confined geometry as well as when cultured on filters (Etoc et al., 2016). It is therefore tempting to speculate that a similar scenario between ligands and inhibitors might be at play. Indeed, ACTIVIN/NODAL inhibitors such as LEFTY1/2 and CERBERUS have also been shown to be induced directly by activation of the SMAD2/3 pathway (Yoney et al., 2018). Interestingly, we did not observe an apical-basal asymmetry in the reception of recombinant WNT3A protein in our RUES2 colonies (Martyn et al., 2019). While this suggests that these types of segregated secretion of ligand/inhibitors might be unique to the TGF $\beta$ signaling pathway, we note 
that in the Drosophila wing, transcytosis of Wnt from the apical to basal compartment and its inhibition by Notum is essential for patterning (Yamazaki et al., 2016). Thus, as in the case of human-specific induction of NOGGIN by BMP4, these might represent specie-specific attributes. Probing signaling dynamics in other polarized epithelia holds the promise of unveiling more surprises.

Stem cell-based, self-organizing models of human development provide a robust tool to discover early aspect of human embryogenesis which otherwise would be impossible to scrutinize (Tyser, 2020). Among many other contributions, these tools allowed for the discovery of polarized signal reception in hESC colonies and its in vivo relevance for BMP4 signaling in the amniotic cavity of the mouse embryo (Etoc et al., 2016; Zhang et al., 2019). This scenario can be reiterated overtime during multiple stages of embryonic development. For example, the early neural tube consists of a polarized epithelium that both sends and receives multiple signals. In mouse, NOGGIN and SHH secreted from the floor plate and notochord impinge on the cells of the ventral neural tube, while BMP4 secreted from the roof plate and ectoderm impinge on the cells of the dorsal neural tube (Brent and Tabin, 2002; McMahon et al., 1998; Ybot-Gonzalez et al., 2007). Thus, polarized secretion and reception may play a role in $\mathrm{D} / \mathrm{V}$ specifications, and subsequently the influence surrounding tissues such as neural crests and somites. Therefore, epithelial polarity represents part of the toolkit used by embryos for robust developmental patterning through secreted molecules.

Acknowledgements:

This work was funded by the National Institutes of Health R01 HD080699 and R01 GM101653. T.P.E was supported by the National Science Foundation Graduate Research Fellowship under Award No. 1946429.

We thank E. Rodriguez-Boulan for discussions about endosomal trafficking, Shu Li for assistance with the secreted NOGGIN western blot, and Samuel Khodursky for assistance with BMP receptor immunostaining. 


\section{Figure Legends}

\section{MAIN FIGURES}

Figure 1: BMP4 is secreted basally and spreads from a local source.

(A) Schematics of polarized hESC epithelium. BMPR localization restricts hESC response to BMP4 to the basolateral domain. (B) Schematics of the doxycycline-inducible constructs for the generation of the xBMP4-overexpressing hESC line. A Myc tag was inserted at the C- terminal of the coding sequence of the mature protein (Cui et al., 2001; Degnin et al., 2004), so that both precursor and mature forms of exogenously expressed BMP4 can be detected by the Myc epitope. A constitutive mCitrine nuclear reporter was added subsequently. (C) BMP4 was secreted to the basolateral media. TRE::xBMP4-myc hESCs were cultured to form a tight epithelium on filter and induced to produce BMP4. After $24 \mathrm{hrs}$, culture media collected from the apical (green) or basal (orange) chambers were analyzed with Western blot. (D) BMP4 signaling propagated in the epithelium as a function of time. pSMAD1/5/8 signaling originated from TRE::BMP4-myc; CAG::H2B-mCitrine cells and propagated to adjacent cells. TRE::xBMP4-myc; CAG::H2B-mCitrine were diluted in wildtype (W'T) hESCs (ratio 1:200) and induced to produce BMP4. pSMAD1 signal intensity was used as a read-out for BMP4 reception in time-course analysis. Exponential fit curves and their corresponding rate constant $\mathrm{K}$ are included. Scale bar $=100 \mu \mathrm{m}$. (E) Quantification of BMP4 signal propagation as a function of time. Error bars = SEM (standard error of mean).

\section{Figure 2: NOGGIN was secreted apically. Apically-delivered recombinant NOGGIN inhibited basal BMP4}

(A) Schematics of the doxycycline-inducible constructs for the generation of the hNOGGINoverexpressing hESC line. A V5 tag was inserted at the N-terminal of the protein-coding sequence (Etoc et al., 2016). A constitutive mCherry nuclear reporter was subsequent added. (B) NOGGIN was secreted to the apical media. TRE::V5-NOGGIN hESCs were cultured on filters to form confluent epithelia and induced to produce NOGGIN for 2, 4, 8, or 24 hours. Media collected from the apical (AP) or basolateral (BL) chambers were collected and analyzed with Western blot. (C) The range of NOGGIN's inhibitory effects extended as a function of time. TRE::V5-NOGGIN hESCs; CAG::H2B-mCherry were diluted in a background of W'T hESCs (ratio 1:200) and induced to secret NOGGIN for the specified times. Then, BMP4 $\left(10 \mathrm{ng} \mathrm{m}^{-1}\right)$ was applied basally for $1 \mathrm{hr}$. pSMAD1 $/ 5 / 8$ labeling demarcated the range of NOGGIN inhibition. Scale bars $=100 \mu \mathrm{m}$. (D) Quantification of NOGGIN inhibitory range as a function of time. The black vertical dashed lines indicate the point where the local slope of the fit changes (maximum of second derivative). Error bars = SEM. (E) NOGGIN inhibitory range as a function of BMP4 concentration. TRE::V5NOGGIN hESCs were diluted in a background of W'T hESCs (ratio 1:200) and induced to secret NOGGIN (8 hr). Then, different concentrations of recombinant BMP4 was applied basally for $1 \mathrm{hr}$. Scale bars $=100 \mu \mathrm{m}$. (F) Quantification of NOGGIN's efficacy in inhibiting pSMAD1/5/8 BMP4 concentration as a function of BMP4 concentration. Exponential fit curves and the inferred scale of exclusion are shown. Error bars $=$ SEM.

\section{Figure 3: Secreted NOGGIN inhibited BMP4 signaling in the epithelium}

(A) Apically-applied recombinant hNOGGIN inhibited $\mathrm{pSMAD} 1 / 5 / 8$ induced by recombinant BMP4. Top row: 1-hr pulse or constant application of recombinant BMP4 (10 $\left.\mathrm{ng} \mathrm{ml}^{-1}\right)$ elicited pSMAD1/5/8 response. Bottom row: This pSMAD1/5/8 response was rapidly inhibited by LDN (a BMP inhibitor that blocks the transcriptional activity of BMPR1 receptors ALK2 and ALK3) (0.1 $\mu \mathrm{M})$ or apically-applied recombinant hNOGGIN $\left(250 \mathrm{ng} \mathrm{ml}^{-1}\right)$. Horizontal axes indicate elapsed 
time following BMP4 application. (B) Apically-applied recombinant hNOGGIN inhibited BMP4 signaling within the epithelium. TRE::xBMP4-myc hESCs; CAG::H2B-mCitrine were mixed with W'T hESCs (ratio 1:200) and induced to produce BMP4 for $22 \mathrm{hr}$. Different concentrations of recombinant hNOGGIN was added to the layer apically or basally for $2 \mathrm{hr} .250 \mathrm{ng} \mathrm{ml}^{-1} \mathrm{NOGGIN}$ efficiently inhibited autonomous pSMAD1/5/8 in BMP4-secreting cells. Scale bar $=100 \mu \mathrm{m}$. (C) Quantification of inhibitory efficacies of apically- and basally-applied recombinant hNOGGIN. Exponential fit curves and the inferred length scale are included. Error bars $=$ SEM.

\section{Figure 4: Apical flow perturbed NOGGIN inhibition in epithelium}

(A) Apical flow did not affect BMP4 signal propagation. A mixture of TRE::BMP4-myc; CAG::H2B-mCitrine and W'T hESCs (ratio 1:500) was cultured overnight in microfluidic chambers. For all experiments in this figure, cells were induced to produce BMP4 under minimal $\left(10 \mu \mathrm{l} \mathrm{hr}{ }^{-1}\right)$ or high apical flow $\left(1000 \mu \mathrm{hr}^{-1}\right)$ conditions for 6 hours, before being stained for pSMAD1/5/8. (B) Quantification of the effect of apical flow on BMP4 signal propagation. Exponential fit curves and the inferred length scale are included. Error bars = SEM. (C) Epithelia with a 1:10 ratio of BMP4 secreting to naive cells exhibited homogenous pSMAD1/5/8 activation under both minimal and high flow conditions. (D) Apical flow perturbed NOGGIN inhibition. A mixture of TRE::V5NOGGIN; CAG::H2B-mCherry, TRE::BMP4-myc; CAG::H2B-mCtrine, and WT hESCs (ratio 1:50:500) was cultured in microfluidic chambers. High apical flow perturbed NOGGIN's long-range inhibitory effects. Error bars $=$ SEM. Scale bars $=100 \mu \mathrm{m}$.

\section{Figure 5: NOGGIN was detected laterally beneath tight junctions and as puncta in receiving cells}

(A) NOGGIN spread to neighboring cells away from secreting cells. A small number of TRE::V5NOGGIN cells were co-cultured with W'T hESCs on filter. Cells were induced to produce NOGGIN for $8 \mathrm{hr}$ before BMP4 $\left(10 \mathrm{ng} \mathrm{ml}^{-1}\right)$ was applied basally for $1 \mathrm{hr}$. NOGGIN immunolabeling was done with $\alpha$-V5 antibodies. White dashed outlines indicate NOGGIN-secreting cells. Top (xy): confocal image of the epithelium through a single Z-plane. Bottom (xz): sagittal view of the same epithelium. Scale bars $=25 \mu \mathrm{m}$. (B) Quantification of total NOGGIN distribution along the Z-axis with respect to ZO-1. Error bars = SD. (C) Sagittal view showing NOGGIN colocalizing with BMPR1a and BMPR2. TRE::V5-NOGGIN cells were co-cultured with TRE::BMPR1A-Myc or TRE::BMPR2-HA hESCs on filter (ratio 1:100). Cells were induced to express NOGGIN and BMPR1A/BMPR2 for $24 \mathrm{hr}$. BMPR1A and BMPR2 labeling was detected by $\alpha$-Myc antibodies and $\alpha$-HA antibodies, respectively. Subsequently, NOGGIN-BMPR colocalization was analyzed in cells at least 1-cell-diameter away from NOGGIN-producing cells. (D) Quantification of \% NOGGIN co-localizing with BMPR1 and BMPR2. Each dot represents \% BMPR pixels overlapping with NOGGIN pixels for various Z-planes. Orange horizontal lines indicate the medians with 95\% confidence intervals. (E) Sagittal view showing NOGGIN localization in the epithelium. TRE::V5-NOGGIN cells were co-cultured with W'T hESCs (ratio 1:200). Cells were induced to express NOGGIN for $24 \mathrm{hr}$. Subsequently, NOGGIN localization was analyzed in cells 5-cell-distance away from NOGGIN-producing cells. Zoom-out panels show transverse views at the corresponding position in Z. NOGGIN appeared as puncta (white arrows) at and below tight junction levels. Error bars $=$ SD. Scale bars $=25 \mu \mathrm{m}$.

\section{Figure 6: NOGGIN was endocytosed at the apical membrane and transported through endosomal compartments}

(A) NOGGIN inhibitory effects on $\mathrm{pSMAD} 1 / 5 / 8$ was eliminated at low temperature. WT-RUES2 were stimulated with basal recombinant BMP4 $\left(50 \mathrm{ng} \mathrm{ml}^{-1}\right.$ ). After $1.5 \mathrm{hr}$, NOGGIN (250 $\mathrm{ng} \mathrm{m}^{-1}$ ) 
was added to the culture either apically or basally, and the culture was kept at $37^{\circ} \mathrm{C}$ or moved to $4{ }^{\circ} \mathrm{C}$. After 2 hrs, cell lysates were collected for Western blot analysis. (B) NOGGIN was apically internalized via dynamin-dependent endocytosis. Recombinant NOGGIN (300 $\mathrm{ng} \mathrm{m}^{-1}$ ) was added apically to WT hESCs with or without dynamin inhibitor Dyngo4a $(100 \mathrm{mM})$. After 2 hrs, cell lysates were collected for Western blot analysis. 2-hr concurrent treatment of Dyngo4a blocked NOGGIN internalization. (C) NOGGIN underwent apical-to-basal transcytosis. NOGGIN-V5conditioned media was applied to the apical compartment for the specified durations. Media from the apical and basal compartments were analyzed with Western blot. The presence of NOGGIN in the basal compartment was detected after 36 hr. (D) NOGGIN colocalized with various endosomal vesicles. 10-kDA Dextran (10-min apical incubation) labeled pinocytotic vesicles. WGA (wheat germ agglutinin) (10-min apical incubation) labeled ASE (Apical Sorting Endosomes). EEA1 antibodies labeled EE (Early Endosomes). Rab11A antibodies labeled ARE (Apical Recycling Endosomes). Transferrin (45-min basal incubation) (Tf 45') labeled CRE (Common Recycling Endosomes). Transferrin (5 min basal incubation) (Tf 5') labeled BSE (Basal Sorting Endosomes). Left: Schema. Right: Data showing two confocal sections in the apical (top) and supranuclear (bottom) regions. Scale bars $=25 \mu \mathrm{m}$. (E) Fraction of NOGGIN (black) co-localizing with endocytotic vesicles at each z-plane with respect to the profile of the respective marker (green, shaded). Fluorescence labeling was binarized. All samples were aligned in Z based on ZO-1 labeling (indicated by red dashed line). Error bars $=$ SD.

Figure 7: Schematics of transcytosis route by which NOGGIN (red) is trafficked from the apical to basolateral extracellular domain.

(Top) Schematics of hESC epithelium on filter

(Bottom) Schematics of NOGGIN transcytosis route

\section{SUPPLEMENTAL FIGURES}

\section{Supplemental Figure 1 (to accompany Figure 2D): Dynamics of apical NOGGIN inhibition} as shown by Western blot of hESC lysates.

(A) WT-RUES2 cultured as a confluent, pseudostratified, polarized epithelium. Cells were seeded with a starting seeding density of $\sim 4,000$ cells $/ \mathrm{mm}^{2} .24 \mathrm{hrs}$ after seeding, cells were fixed and stained for markers of tight junctions (ZO-1) and actin (Phalloidin). Scale bars $=50 \mu \mathrm{m}$. (B) Cells kept a "memory" of NOGGIN for 3 hours. Pre-treatment of hESCs with apical NOGGIN for $(250 \mathrm{ng} \mathrm{ml}$ ${ }^{1} ; 2 \mathrm{hr}$ ) was sufficient to inhibit pSMAD1/5/8 induced by basal BMP4 (10 $\left.\mathrm{ng} \mathrm{ml}^{-1} ; 1 \mathrm{hr}\right)$ up to 3 hours later. (C) pSMAD1/5/8 induced by basally-applied recombinant BMP4 was inhibited by apically- and basally-applied recombinant NOGGIN. W'T hESCs were induced by a 1.5 -hr pulse of BMP4 (10 $\mathrm{ng} \mathrm{ml}^{-1}$ ). Subsequently, BMP4 was washed out and simultaneously NOGGIN (250 ng ml

$\left.{ }^{1}\right)$ was applied apically or basally for $2 \mathrm{hr}$. Cell lysates were collected to analyze with Western blot. (The first experiment in (C) is a control with no added NOGGIN).

\section{Supplemental Figure 2: Schematics of microfluidic device}

A PDMS layer (red), cast from a custom 3D-printed mold, was sandwiched between two glass slides to form a tightly-sealed chamber. Chamber dimensions were $55 \mathrm{~mm}$ x $2 \mathrm{~mm}$ x $0.5 \mathrm{~mm}$. The top slide has drilled inlet and outlet holes. The culture chamber and tubing were securely fastened by a custom clamping device. (A) Top view. (B) Side view. (C) The calculated Reynold's numbers for the two flow conditions show that the flow inside the chamber was laminar. The wall shear stress at the highest flow rate assuming a flow proportional to $\mathrm{z}(\mathrm{h}-\mathrm{z})$ where $\mathrm{h}=0.5 \mathrm{~mm}$ is the channel height is of order 0.03 dynes $/ \mathrm{cm}^{2}$. 


\section{Supplemental Figure 3 (to accompany Figure 4):}

(A) hESCs maintained pluripotency under minimal flow in microfluidic culture. After hESCs were cultured on glass-bottomed microfluidic chamber under minimal flow $\left(10 \mathrm{ml} \mathrm{hr^{-1 }}\right)$ overnight, the flow rate was increased to $1000 \mathrm{ul} \mathrm{hr}^{-1}$ (High flow) for $9 \mathrm{hr}$. Cells were stained for pluripotency markers OCT3/4, SOX2, and NANOG (B) Cells were also stained for tight junction markers ZO1. (C) BMP4 signaling propagated on glass substrate. TRE::xBMP4-myc cells were co-cultured with W'T hESCs (ratio 1:200) on glass micropatterned chip. The cells were induced to produce BMP4 for the specified durations. pSMAD1/5/8 immunolabeling defined the range of BMP4 signaling. (D) Quantification of BMP4 signaling propagation as a function of time on glass substrates. The rate of spreading is comparable to cells on filters in Fig 1E. Error bars $=$ SD. Scale bars $=100 \mu \mathrm{m}$. (E) Intense V5 labeling overlapping with Golgi marker GIANTIN (Linstedt and Hauri, 1993) indicates TRE::hNOGGIN-V5 cells.

\section{Supplemental Figure 4 (to accompany Figure 6A, B):}

(A) Dynamin-dependent endocytosis of BMP4 was not required for BMP4 signaling W'T hESCs were stimulated with BMP4 (50 $\mathrm{ng} \mathrm{m}^{-1} ; 30 \mathrm{~min}$ ) with or without 30-min pre-treatment of Dyngo4a $(100 \mathrm{mM})$ The drug did not affect the response to basal BMP4. Cell lysates were collected for Western blot analysis. (B) Cells maintained normal ZO-1 expression following transcytosis experiment. Following transcytosis experiment in Figure $6 \mathrm{~B}$, the same epithelia were evaluated for expression pattern of tight junction marker ZO-1. All epithelia examined showed an intact mesh of ZO-1. Scale bar $=100 \mu \mathrm{m}$. (C) Epithelia were impermeable to 40-kDA dextran after the transcytosis experiment. Following transcytosis experiment in Figure 6B, the same epithelia was evaluated for epithelial permeability at the corresponding times. $40-\mathrm{kDA}$ dextran-TxRed $(25 \mathrm{mg} / \mathrm{ml})$ was added to the apical chamber, for 1 hour $\left(37^{\circ} \mathrm{C}, 5 \% \mathrm{CO} 2\right)$, with or without a pre-treatment of chelating agent EDTA $(50 \mathrm{mM}, 30 \mathrm{~min})$. Fluorescence intensity in the basolateral compartment was measured by a fluorometer (NanoDrop 2000), set at an absorbance of $589 \mathrm{~nm}$. Epithelial permeability was assessed by measuring the TxRed-labeled dextran flux from the apical to the basolateral chambers. (D) Epithelium integrity was maintained during $48 \mathrm{hrs}$ filter culture. We compared the permeability of epithelia seeded with 200,000 hESCs (standard culture condition used throughout this study) and epithelia seeded with 50,000 hESCs. While the epithelia prepared with standard protocol demonstrated impermeability, the epithelia seeded with less cells demonstrated leakiness: 40-kDA Dextran-FITC added to the top media was found in the basal media in the latter condition but not the first.

Supplemental Figure 5 (to accompany Figure 6C,D): Distribution of ZO-1, NOGGIN, and NOGGIN-endosome overlap as a function of $Z$ across different samples, each labeled with a different endosome marker.

(A) Profile of NOGGIN distribution along the $Z$-axis for each data set corresponding to a different endosomal marker. The area under the curve indicates total NOGGIN labeling $(100 \%)$. (B) Profile of ZO-1 distribution along the $Z$-axis for each data set corresponding to a different endosomal marker. For each field of view, the peak of the curve was set as the 0 -point of $Z$. The distribution of all other markers were aligned to this point of reference. The area under the curve indicates total ZO-1 labeling (100\%). (C) Distribution of all NOGGIN-endosome co-labeled regions along the Zaxis. The area under the curve indicates all total overlap area $(100 \%)$. (D) Fraction of endosome marker co-localizing with NOGGIN (black) with respect to the distribution of each marker (blue, shaded) in Z. (This is the reciprocal of the normalization in Fig 6D). Fluorescence labeling was binarized. All samples were aligned in Z based on ZO-1 labeling (indicated by red dashed line). In all analysis, fluorescence labeling was binarized. All samples were aligned in Z based on ZO-1 labeling. 
Refs:

Arnold, S.J., and Robertson, E.J. (2009). Making a commitment: cell lineage allocation and axis patterning in the early mouse embryo. Nat Rev Mol Cell Biol 10, 91-103.

Ballermann, B.J., Dardik, A., Eng, E., and Liu, A. (1998). Shear stress and the endothelium. Kidney Int Suppl 67, S100-108.

Brent, A.E., and Tabin, C.J. (2002). Developmental regulation of somite derivatives: muscle, cartilage and tendon. Curr Opin Genet Dev 12, 548-557.

Brown, P.S., Wang, E., Aroeti, B., Chapin, S.J., Mostov, K.E., and Dunn, K.W. (2000). Definition of distinct compartments in polarized Madin-Darby canine kidney (MDCK) cells for membrane-volume sorting, polarized sorting and apical recycling. Traffic 1, 124-140.

Brunner, P., Hastar, N., Kaehler, C., Burdzinski, W., Jatzlau, J., and Knaus, P. (2020). AMOT130 drives BMP-SMAD signaling at the apical membrane in polarized cells. Mol Biol Cell 31, 118-130.

Cresawn, K.O., Potter, B.A., Oztan, A., Guerriero, C.J., Ihrke, G., Goldenring, J.R., Apodaca, G., and Weisz, O.A. (2007). Differential involvement of endocytic compartments in the biosynthetic traffic of apical proteins. EMBO J 26, 3737-3748.

Crick, F. (1970). Diffusion in Embryogenesis. Nature 225, 420-\&.

Cui, Y., Hackenmiller, R., Berg, L., Jean, F., Nakayama, T., Thomas, G., and Christian, J.L. (2001). The activity and signaling range of mature BMP-4 is regulated by sequential cleavage at two sites within the prodomain of the precursor. Genes Dev 15, 2797-2802.

Degnin, C., Jean, F., Thomas, G., and Christian, J.L. (2004). Cleavages within the prodomain direct intracellular trafficking and degradation of mature bone morphogenetic protein-4. Mol Biol Cell 15, 5012-5020.

Etoc, F., Metzger, J., Ruzo, A., Kirst, C., Yoney, A., Ozair, M.Z., Brivanlou, A.H., and Siggia, E.D. (2016). A Balance between Secreted Inhibitors and Edge Sensing Controls Gastruloid Self-Organization. Dev Cell 39, 302-315.

Gilmour, D., Rembold, M., and Leptin, M. (2017). From morphogen to morphogenesis and back. Nature 541, 311-320.

Hartung, A., Bitton-Worms, K., Rechtman, M.M., Wenzel, V., Boergermann, J.H., Hassel, S., Henis, Y.I., and Knaus, P. (2006). Different routes of bone morphogenic protein (BMP) receptor endocytosis influence BMP signaling. Mol Cell Biol 26, 7791-7805.

Hidalgo, D.A.H., Z.; Romanova-Michaelides, M.; González-Gaitán, M.; Jülicher F. (2019). Dynamic modes of morphogen transport. arXiv 1909.13280.

Knight, A., Hughson, E., Hopkins, C.R., and Cutler, D.F. (1995). Membrane protein trafficking through the common apical endosome compartment of polarized Caco-2 cells. Mol Biol Cell 6, 597-610. 
Kornberg, T.B. (2017). Distributing signaling proteins in space and time: the province of cytonemes. Curr Opin Genet Dev 45, 22-27.

Lapierre, L.A., Ducharme, N.A., Drake, K.R., Goldenring, J.R., and Kenworthy, A.K. (2012). Coordinated regulation of caveolin-1 and Rab11a in apical recycling compartments of polarized epithelial cells. Exp Cell Res 318, 103-113.

Li, L., Wan, T., Wan, M., Liu, B., Cheng, R., and Zhang, R. (2015). The effect of the size of fluorescent dextran on its endocytic pathway. Cell Biol Int 39, 531-539.

Linstedt, A.D., and Hauri, H.P. (1993). Giantin, a novel conserved Golgi membrane protein containing a cytoplasmic domain of at least $350 \mathrm{kDa}$. Mol Biol Cell 4, 679-693.

Martyn, I., Brivanlou, A.H., and Siggia, E.D. (2019). A wave of WNT signaling balanced by secreted inhibitors controls primitive streak formation in micropattern colonies of human embryonic stem cells. Development 146.

Matos, I., Asare, A., Levorse, J., Ouspenskaia, T., de la Cruz-Racelis, J., Schuhmacher, L.N., and Fuchs, E. (2020). Progenitors oppositely polarize WNT activators and inhibitors to orchestrate tissue development. Elife 9.

McCluskey, A., Daniel, J.A., Hadzic, G., Chau, N., Clayton, E.L., Mariana, A., Whiting, A., Gorgani, N.N., Lloyd, J., Quan, A., et al. (2013). Building a better dynasore: the dyngo compounds potently inhibit dynamin and endocytosis. Traffic 14, 1272-1289.

McMahon, J.A., Takada, S., Zimmerman, L.B., Fan, C.M., Harland, R.M., and McMahon, A.P. (1998). Noggin-mediated antagonism of BMP signaling is required for growth and patterning of the neural tube and somite. Genes Dev 12, 1438-1452.

Morgan, T.H. (1901). Regeneration in the egg, embryo, and adult. Am Nat 35, 949-973.

Muller, P., Rogers, K.W., Yu, S.R., Brand, M., and Schier, A.F. (2013). Morphogen transport. Development 140, 1621-1638.

Nallet-Staub, F., Yin, X., Gilbert, C., Marsaud, V., Ben Mimoun, S., Javelaud, D., Leof, E.B., and Mauviel, A. (2015). Cell density sensing alters TGF-beta signaling in a cell-type-specific manner, independent from Hippo pathway activation. Dev Cell 32, 640-651.

O'Rahilly, R., and Muller, F. (2010). Developmental stages in human embryos: revised and new measurements. Cells Tissues Organs 192, 73-84.

Odorizzi, G., Pearse, A., Domingo, D., Trowbridge, I.S., and Hopkins, C.R. (1996). Apical and basolateral endosomes of MDCK cells are interconnected and contain a polarized sorting mechanism. J Cell Biol 135, 139-152.

Ohkawara, B., lemura, S., ten Dijke, P., and Ueno, N. (2002). Action range of BMP is defined by its $\mathrm{N}$-terminal basic amino acid core. Curr Biol 12, 205-209. 
Paarmann, P., Dorpholz, G., Fiebig, J., Amsalem, A.R., Ehrlich, M., Henis, Y.I., Muller, T., and Knaus, P. (2016). Dynamin-dependent endocytosis of Bone Morphogenetic Protein2 (BMP2) and its receptors is dispensable for the initiation of Smad signaling. Int J Biochem Cell Biol 76, 51-63.

Paine-Saunders, S., Viviano, B.L., Economides, A.N., and Saunders, S. (2002). Heparan sulfate proteoglycans retain Noggin at the cell surface: a potential mechanism for shaping bone morphogenetic protein gradients. J Biol Chem 277, 2089-2096.

Perez Bay, A.E., Schreiner, R., Benedicto, I., Paz Marzolo, M., Banfelder, J., Weinstein, A.M., and Rodriguez-Boulan, E.J. (2016). The fast-recycling receptor Megalin defines the apical recycling pathway of epithelial cells. Nat Commun 7, 11550.

Rider, C.C., and Mulloy, B. (2017). Heparin, Heparan Sulphate and the TGF-beta Cytokine Superfamily. Molecules 22.

Rodriguez-Boulan, E., Kreitzer, G., and Musch, A. (2005). Organization of vesicular trafficking in epithelia. Nat Rev Mol Cell Biol 6, 233-247.

Rodriguez-Boulan, E., and Macara, I.G. (2014). Organization and execution of the epithelial polarity programme. Nat Rev Mol Cell Biol 15, 225-242.

Rogers, K.W., and Schier, A.F. (2011). Morphogen Gradients: From Generation to Interpretation. Annu Rev Cell Dev Bi 27, 377-407.

Sheff, D.R., Daro, E.A., Hull, M., and Mellman, I. (1999). The receptor recycling pathway contains two distinct populations of early endosomes with different sorting functions. J Cell Biol 145, 123-139.

Simonsen, A., Lippe, R., Christoforidis, S., Gaullier, J.M., Brech, A., Callaghan, J., Toh, B.H., Murphy, C., Zerial, M., and Stenmark, H. (1998). EEA1 links PI(3)K function to Rab5 regulation of endosome fusion. Nature 394, 494-498.

Simunovic, M., Metzger, J.J., Etoc, F., Yoney, A., Ruzo, A., Martyn, I., Croft, G., You, D.S., Brivanlou, A.H., and Siggia, E.D. (2019). A 3D model of a human epiblast reveals BMP4-driven symmetry breaking. Nat Cell Biol 21, 900-910.

Smith, W.C., and Harland, R.M. (1992). Expression cloning of noggin, a new dorsalizing factor localized to the Spemann organizer in Xenopus embryos. Cell 70, 829-840.

Sorre, B., Warmflash, A., Brivanlou, A.H., and Siggia, E.D. (2014). Encoding of temporal signals by the TGF-beta pathway and implications for embryonic patterning. Dev Cell 30, 334-342. $212,430-\&$.

Stumpf, H.F. (1966). Mechanism by Which Cells Estimate Their Location within Body. Nature

Tyser, R.C.V.M., E.; Nakanoh S.; Vallier, L.; Scialdone, A.; Srinivas A. (2020). A spatially resolved single cell atlas of human gastrulation. bioRxiv.

Warmflash, A., Arduini, B.L., and Brivanlou, A.H. (2012). The molecular circuitry underlying pluripotency in embryonic stem cells. Wiley Interdiscip Rev Syst Biol Med 4, 443-456. 
Wartlick, O., Julicher, F., and Gonzalez-Gaitan, M. (2014). Growth control by a moving morphogen gradient during Drosophila eye development. Development 141, 1884-1893.

Wartlick, O., Kicheva, A., and Gonzalez-Gaitan, M. (2009). Morphogen gradient formation. Cold Spring Harb Perspect Biol 1, a001255.

Yamazaki, Y., Palmer, L., Alexandre, C., Kakugawa, S., Beckett, K., Gaugue, I., Palmer, R.H., and Vincent, J.P. (2016). Godzilla-dependent transcytosis promotes Wingless signalling in Drosophila wing imaginal discs. Nat Cell Biol 18, 451-457.

Ybot-Gonzalez, P., Savery, D., Gerrelli, D., Signore, M., Mitchell, C.E., Faux, C.H., Greene, N.D., and Copp, A.J. (2007). Convergent extension, planar-cell-polarity signalling and initiation of mouse neural tube closure. Development 134, 789-799.

Yoney, A., Etoc, F., Ruzo, A., Carroll, T., Metzger, J.J., Martyn, I., Li, S., Kirst, C., Siggia, E.D., and Brivanlou, A.H. (2018). WNT signaling memory is required for ACTIVIN to function as a morphogen in human gastruloids. Elife 7.

Zhang, Z., Zwick, S., Loew, E., Grimley, J.S., and Ramanathan, S. (2019). Mouse embryo geometry drives formation of robust signaling gradients through receptor localization. Nat Commun 10, 4516.

Zimmerman, L.B., De Jesus-Escobar, J.M., and Harland, R.M. (1996). The Spemann organizer signal noggin binds and inactivates bone morphogenetic protein 4. Cell 86, 599-606. 


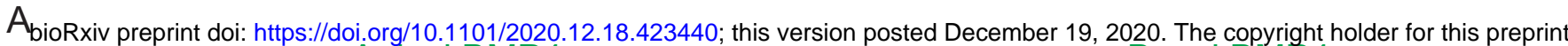

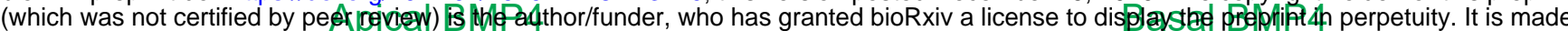
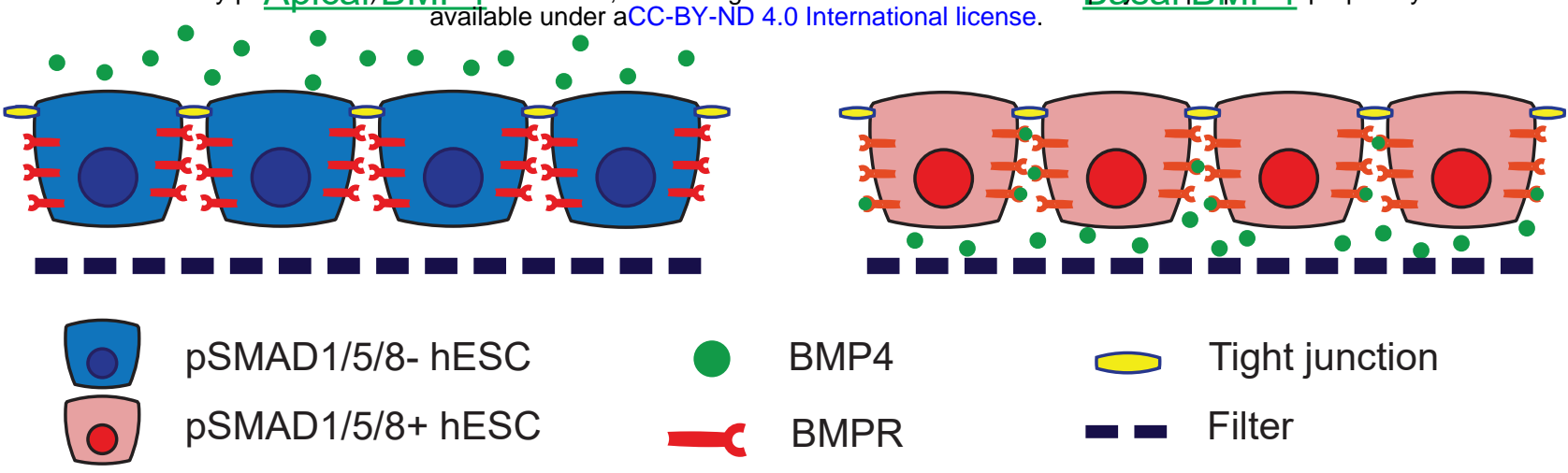

B

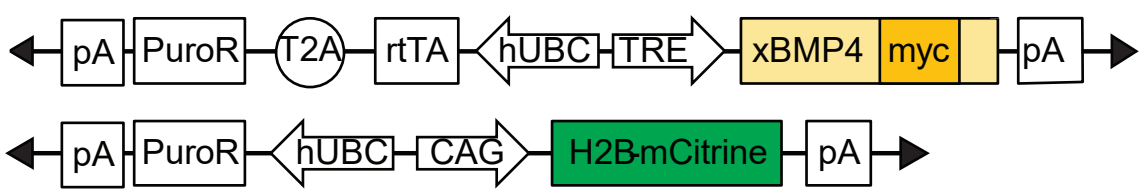

C

D

\section{DAPI mCitrine pSMAD1/5/8}

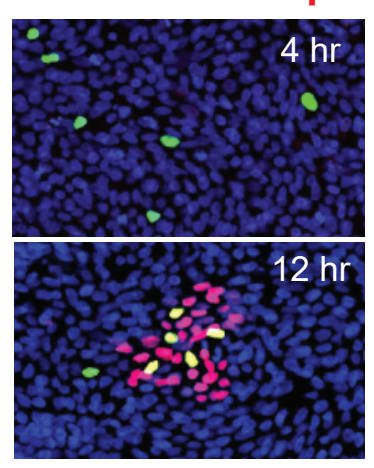

E

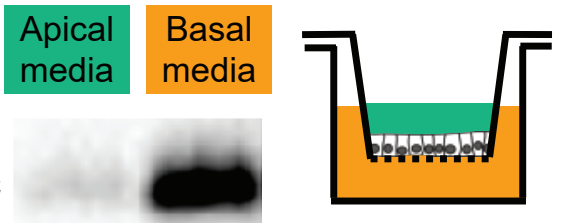

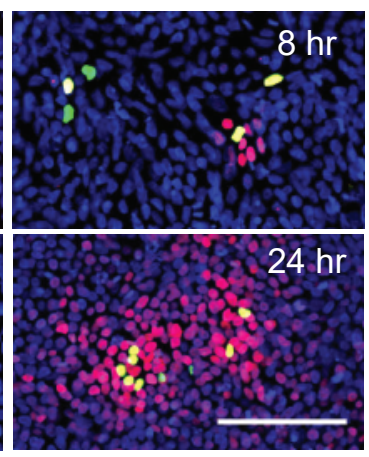

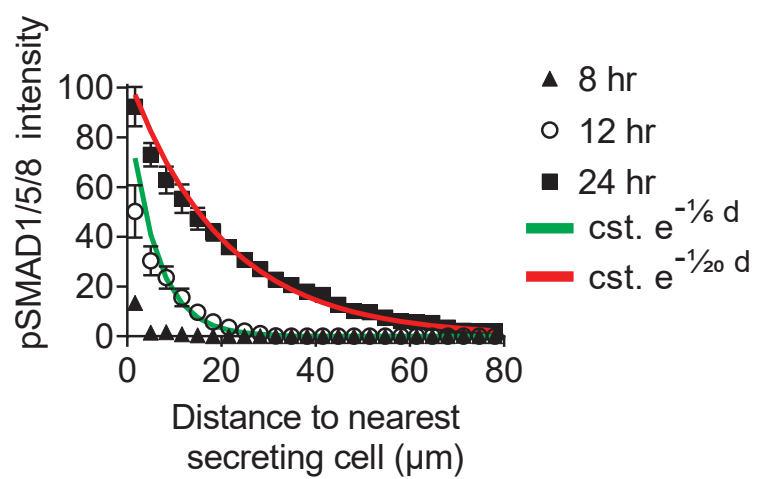


AbioRxiv preprint doi: https://doi.org/10.1101/2020.12.18.423440; this version posted Decembe解, 2020. The copyright holder for this preprint (which was not certified by peer review) is the author/funder, who has granted bioRxiv a license to display the preprint in perpetuity. It is made

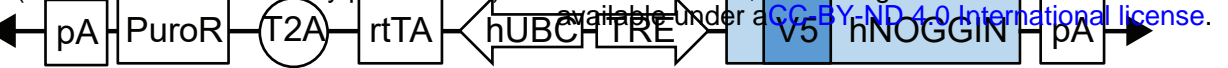

$4 \mathrm{pA}-\mathrm{BsdR} \longrightarrow \mathrm{hUBC}-\mathrm{CAG}-\mathrm{H}$-mCherry $\mathrm{pA} \rightarrow$

C

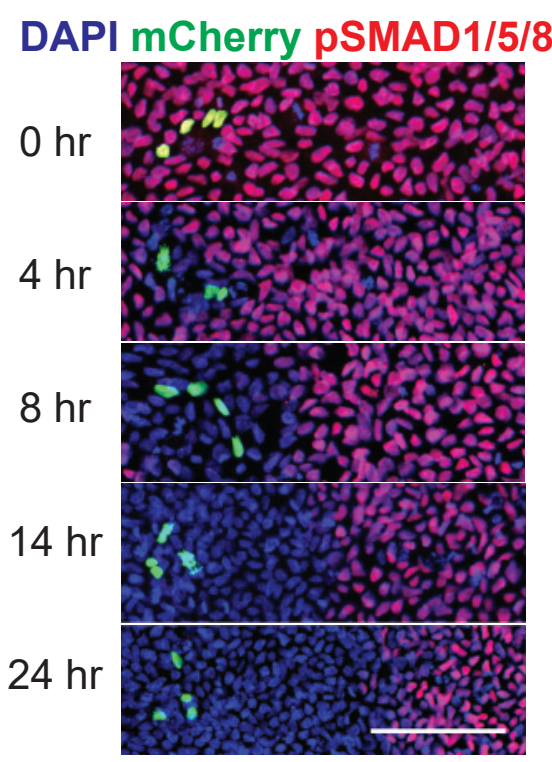

E
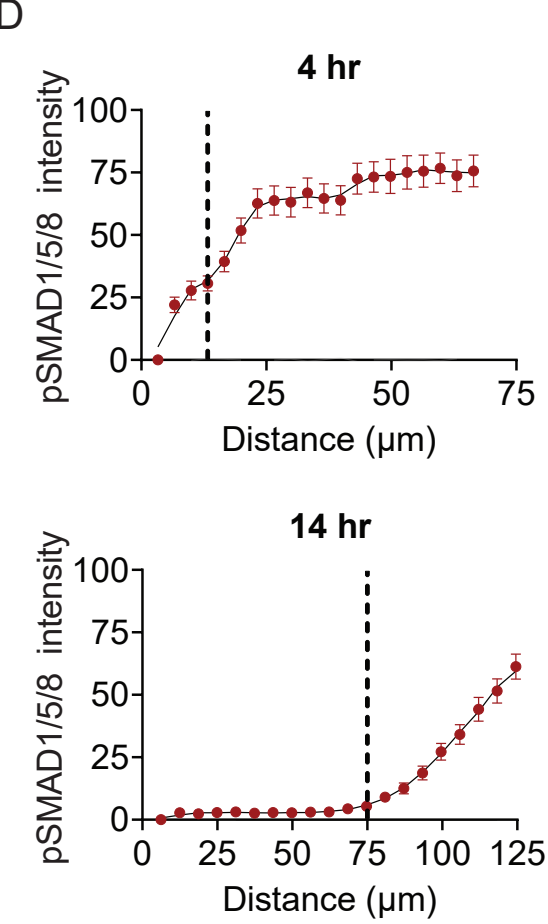

V5

$\frac{2 \mathrm{hr}}{\text { AP BL AP BL AP BL AP BL }} \frac{4 \mathrm{hr}}{8 \mathrm{hr}} \frac{24 \mathrm{hr}}{\text { AP }}$

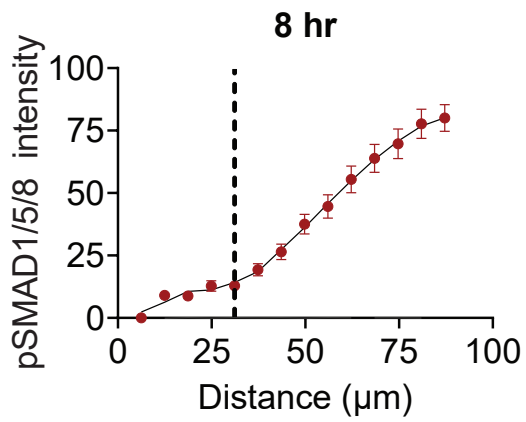

$24 \mathrm{hr}$

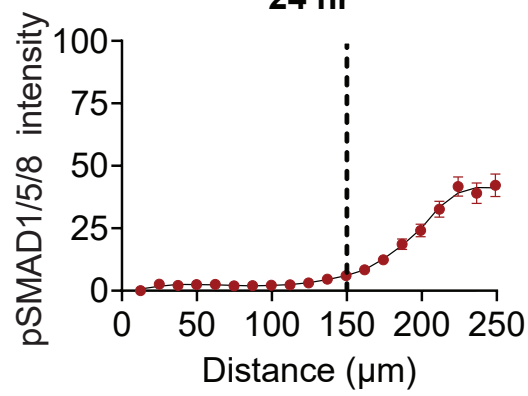

Basal BMP4 concentration

$50 \mathrm{ng} \mathrm{ml}^{-1}$

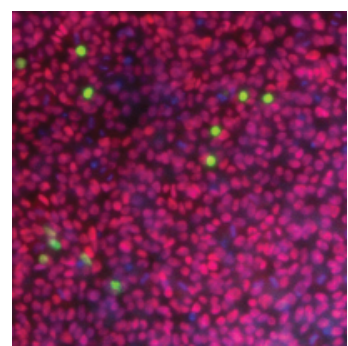

$25 \mathrm{ng} \mathrm{ml}^{-1}$

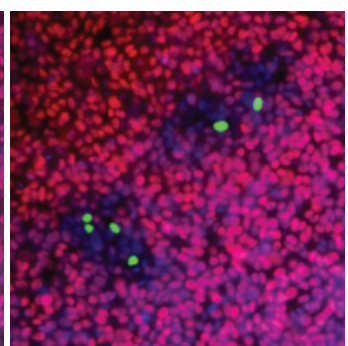

$12.5 \mathrm{ng} \mathrm{ml}^{-1}$

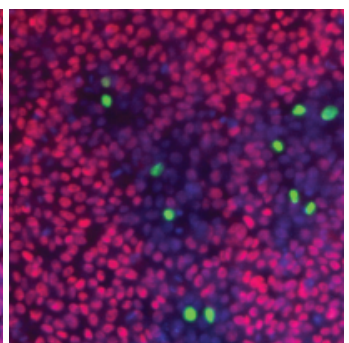

$6.25 \mathrm{ng} \mathrm{ml}^{-1}$

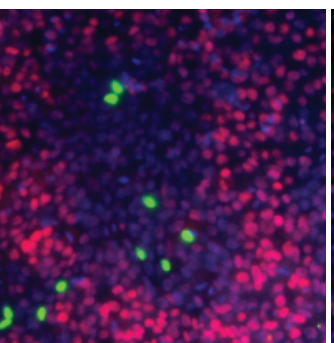

$3 \mathrm{ng} \mathrm{ml}^{-1}$

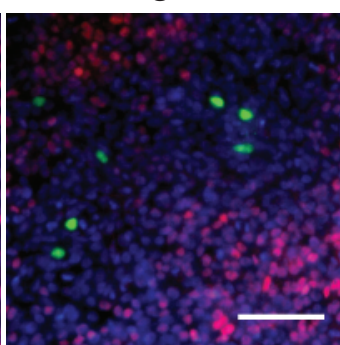

DAPI mCherry pSMAD1/5/8

F

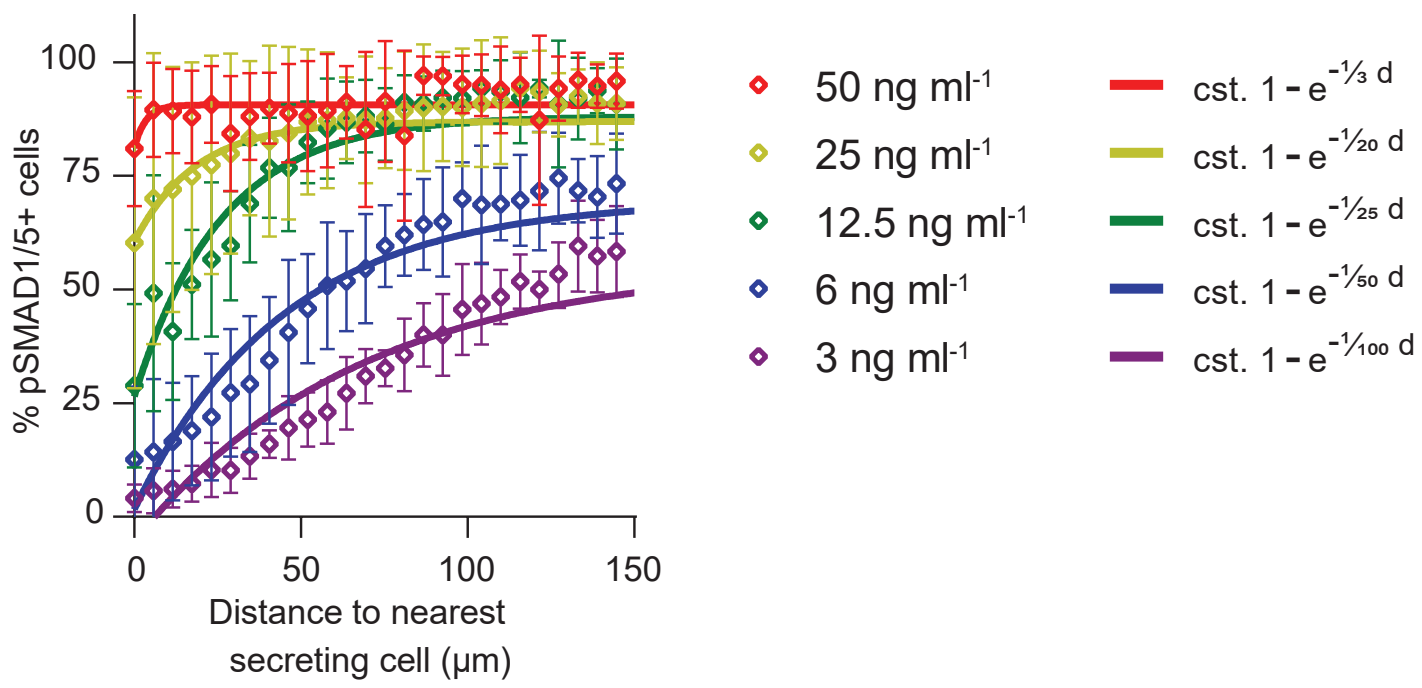


AbioRxiv preprint doi: https://doi.org/10.1101/2020.12.18.423440; this version posted December 19, 2020. The copyright holder for this preprint (which wasnot certified by peer review) is the author/funder, who has granted bioRxiv a license to display the preprint in perpetuity. It is made

\section{BMP4}

$\underset{\text { Elapsed time after BMP4 application (hr) }}{\longrightarrow}$

pSMAD1/5/8

Vinculin

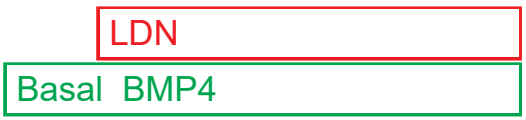

Elapsed time after BMP4 application (hr)

pSMAD $1 / 5 / 8$

Vinculin

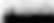

(3)

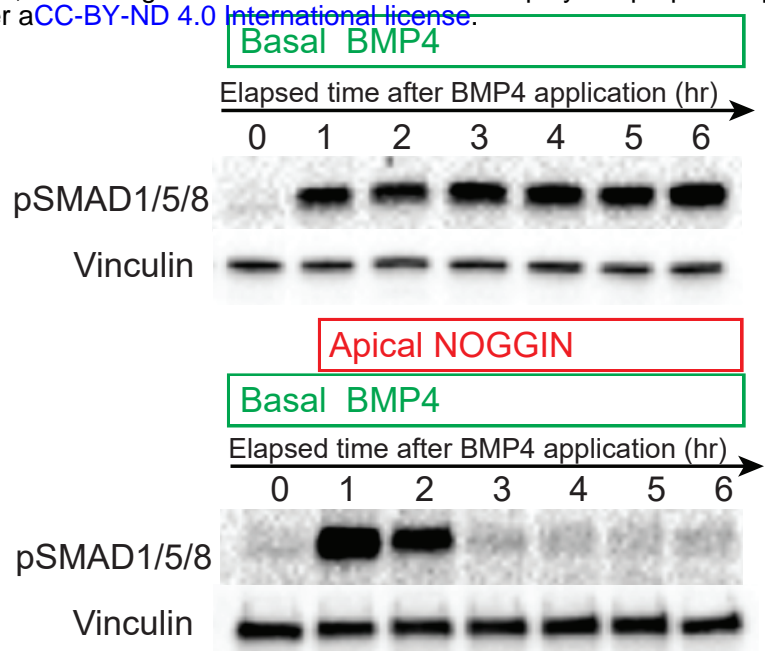

\begin{tabular}{ccccccc}
\multicolumn{5}{l}{ Elapsed time after } & BMP4 application $(\mathrm{hr})$ \\
\hline & 1 & 2 & 3 & 4 & 5 & 6
\end{tabular}
B

BMP4-secreting cell

(0) pSMAD $1 / 5 / 8+$ cell

- pSMAD1/5/8- cell

No NOGGIN

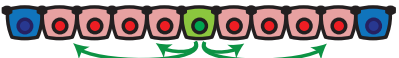

crerer

Apical NOGGIN

NOGGIN

Basal NOGGIN

Crerererorerere TL TL TS TIN

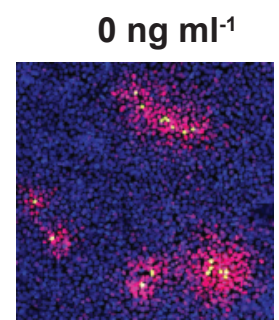

DAPI

mCitrine

pSMAD1/5/8

$10 \mathrm{ng} \mathrm{ml}^{-1}$

$50 \mathrm{ng} \mathrm{ml}^{-1}$ $250 \mathrm{ng} \mathrm{ml}^{-1}$
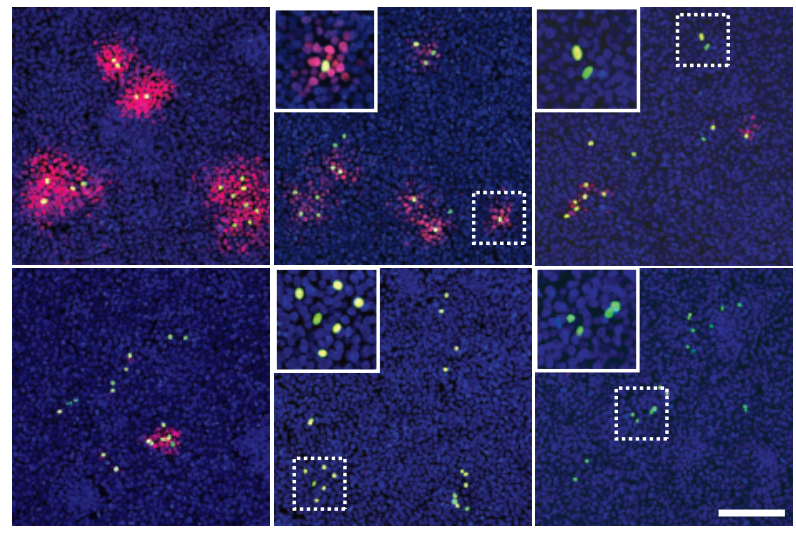

C

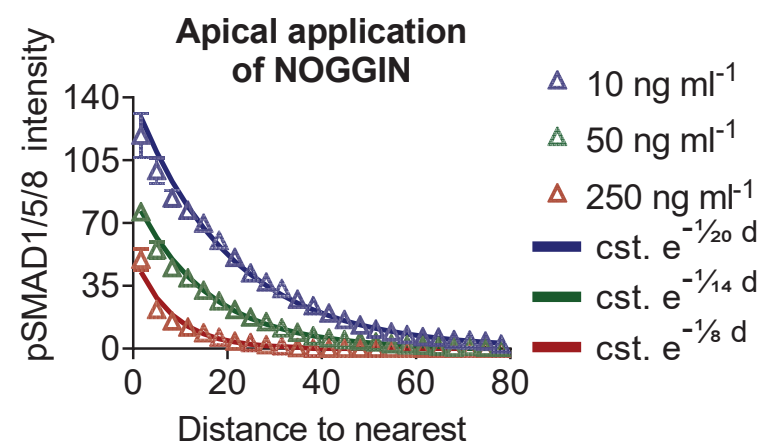

secreting cell $(\mu \mathrm{m})$

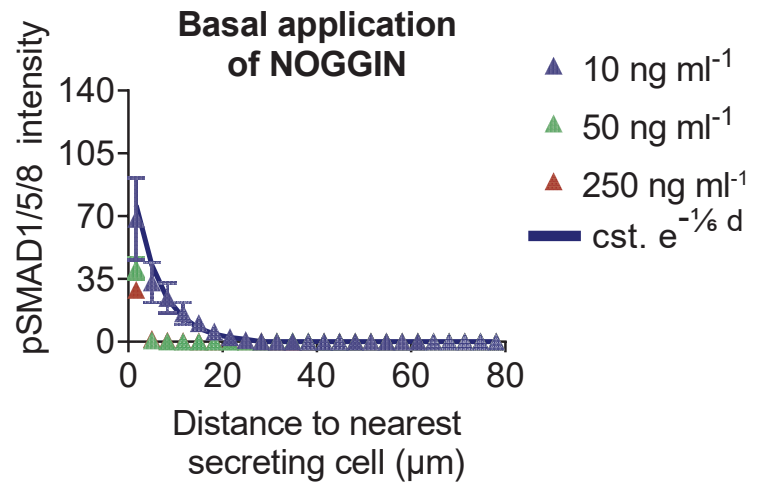


bAARxiv preprint doi: https://doi.org/10.1101/2020.12.18.423440; this version posted December 19, 2020. The copyright holder for this preprint (which was not certified by peer review) is the author/funder, who has granted bioRxiv a license to display the preprint in perpetuity. It is made available Ander aCC-BY-ND 4.0 International license,8 Merged
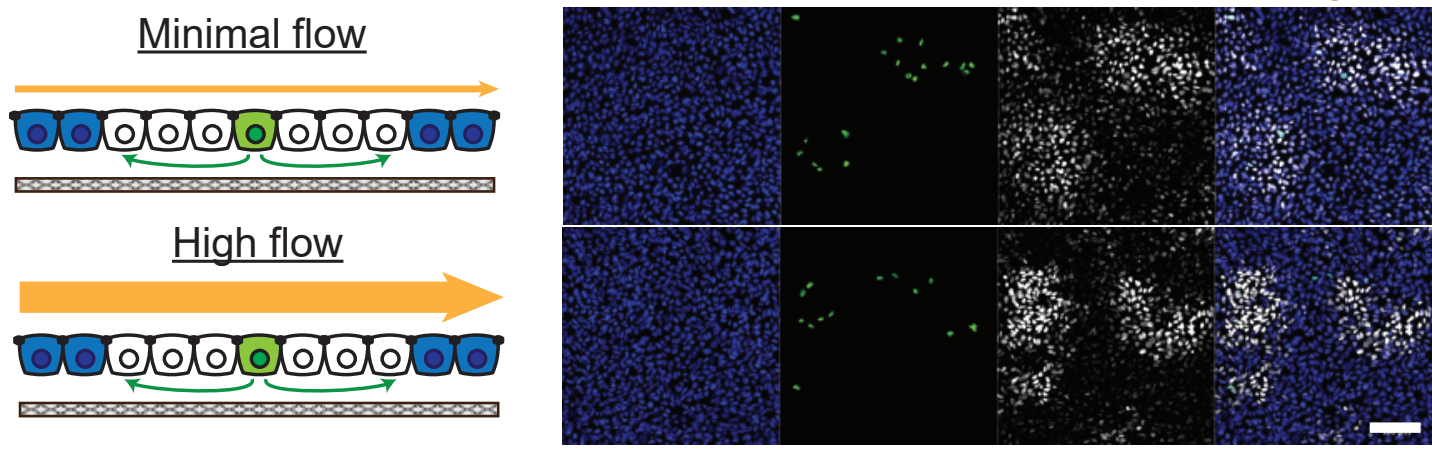

B

$\begin{array}{ll}\longrightarrow & \text { Minimal flow }\left(10 \mathrm{ul} \mathrm{hr}^{-1}\right) \\ \text { High apical flow }\left(1000 \mathrm{ul} \mathrm{hr}^{-1}\right) \\ \text { pSMAD1/5/8- cell } \\ \text { pSMAD1/5/8+ cell } \\ \text { BMP4-secreting cell } \\ \text { NOGGIN-secreting cell } \\ \text { Glass substrate }\end{array}$

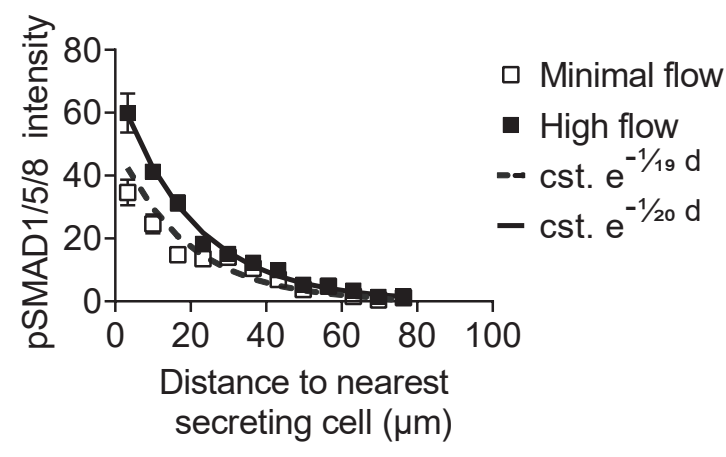

C
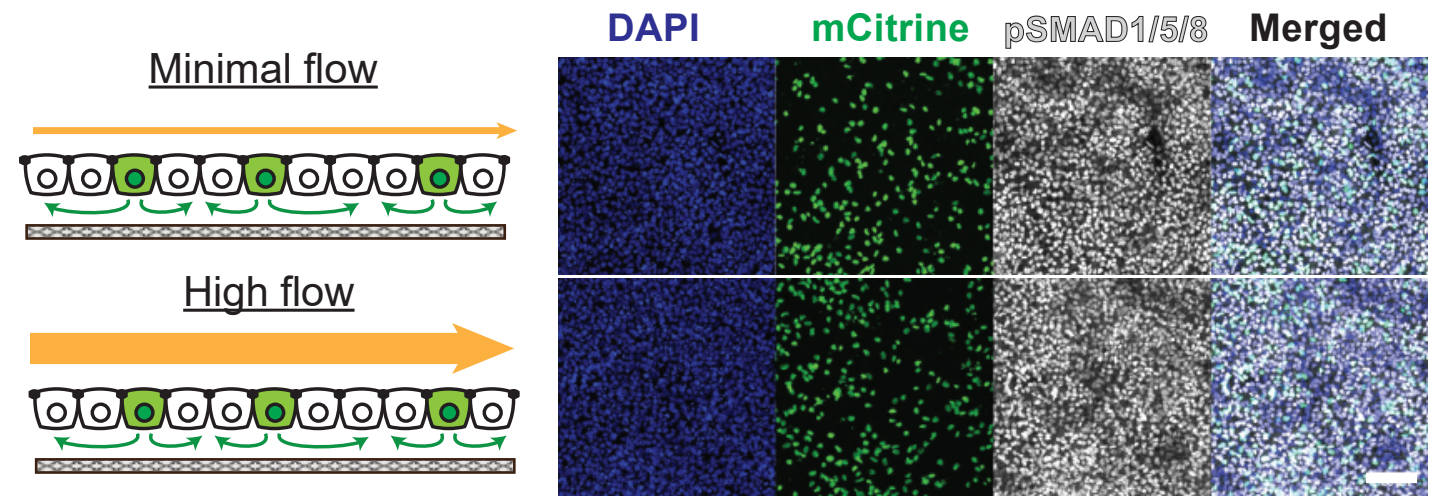

D
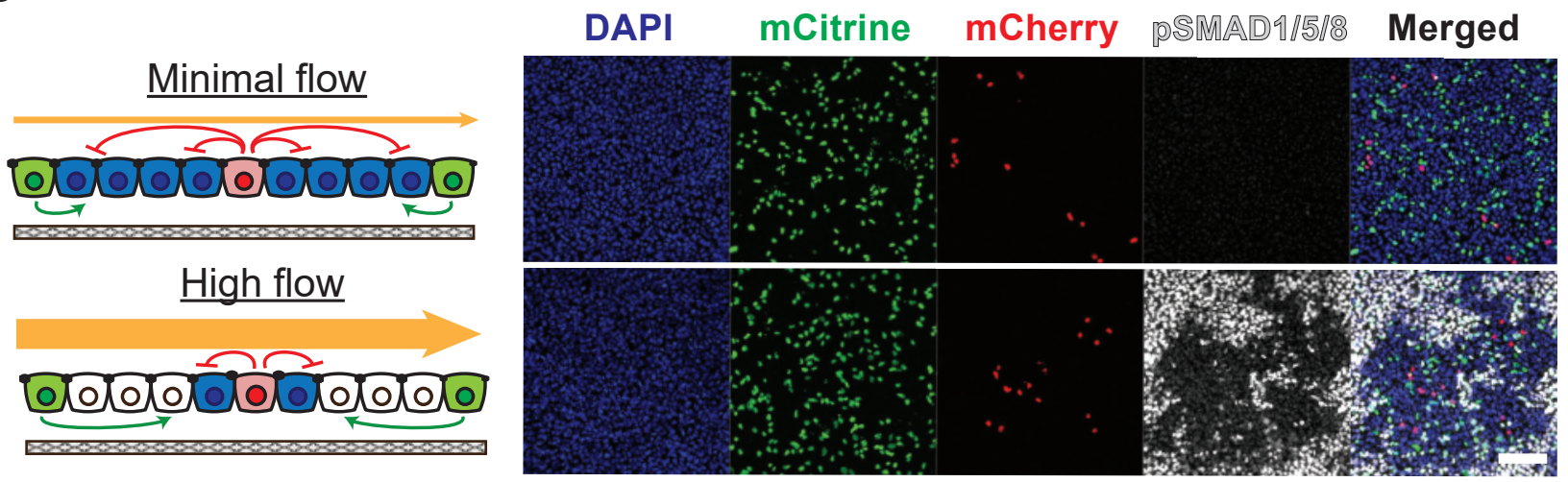


\section{F 5}

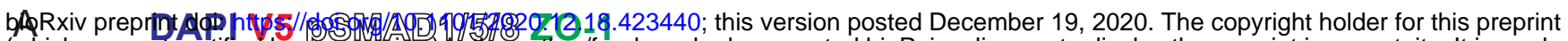
(which was not certified by peer review) is the author/funder, who has granted bioRxiv a license to display the preprint in perpetuity. It is made

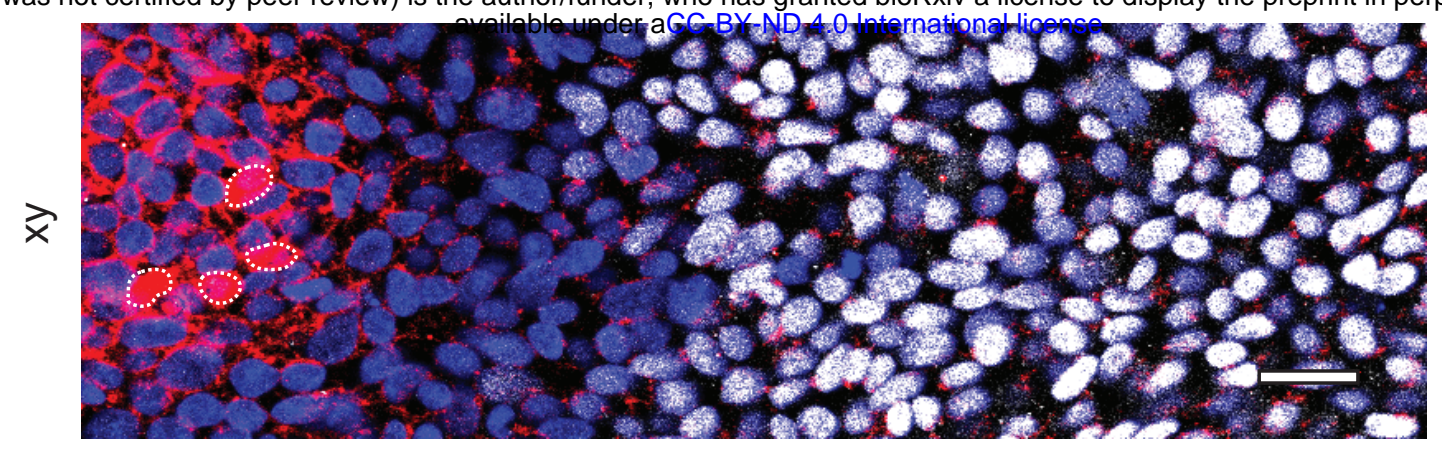

$\mathrm{X}$

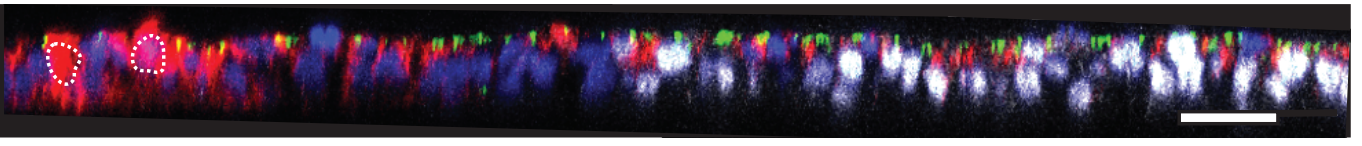

B

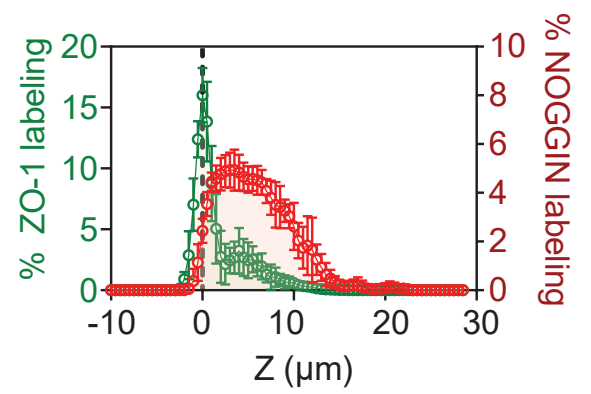

C

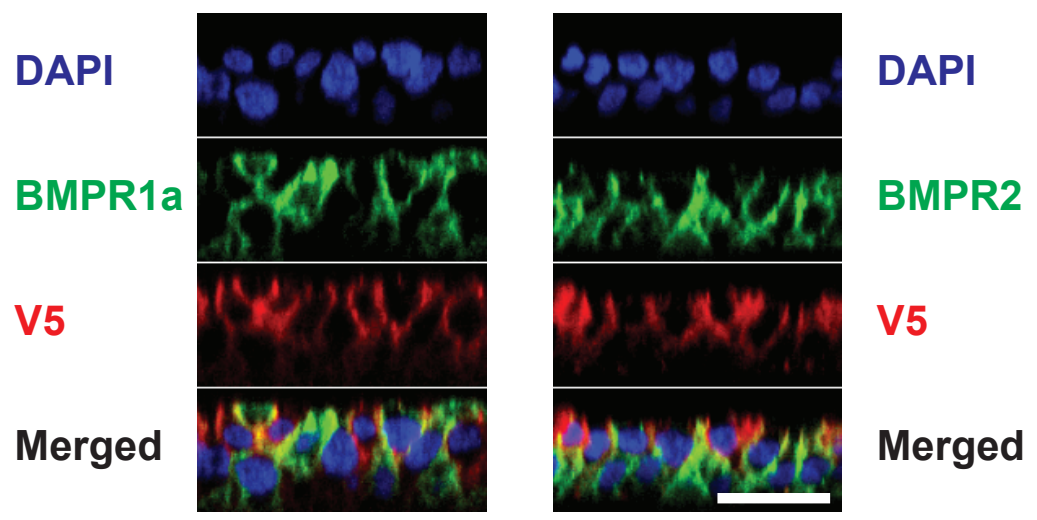

$\%$ BMPR Colocalization to NOGGIN

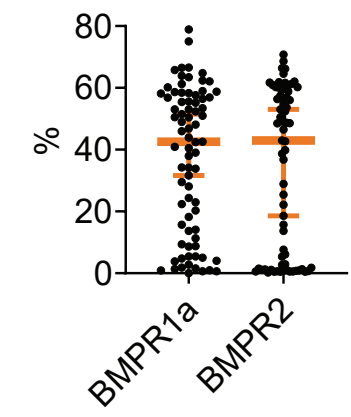

$E$

DAPI ZO-1 V5

ZO-1 V5
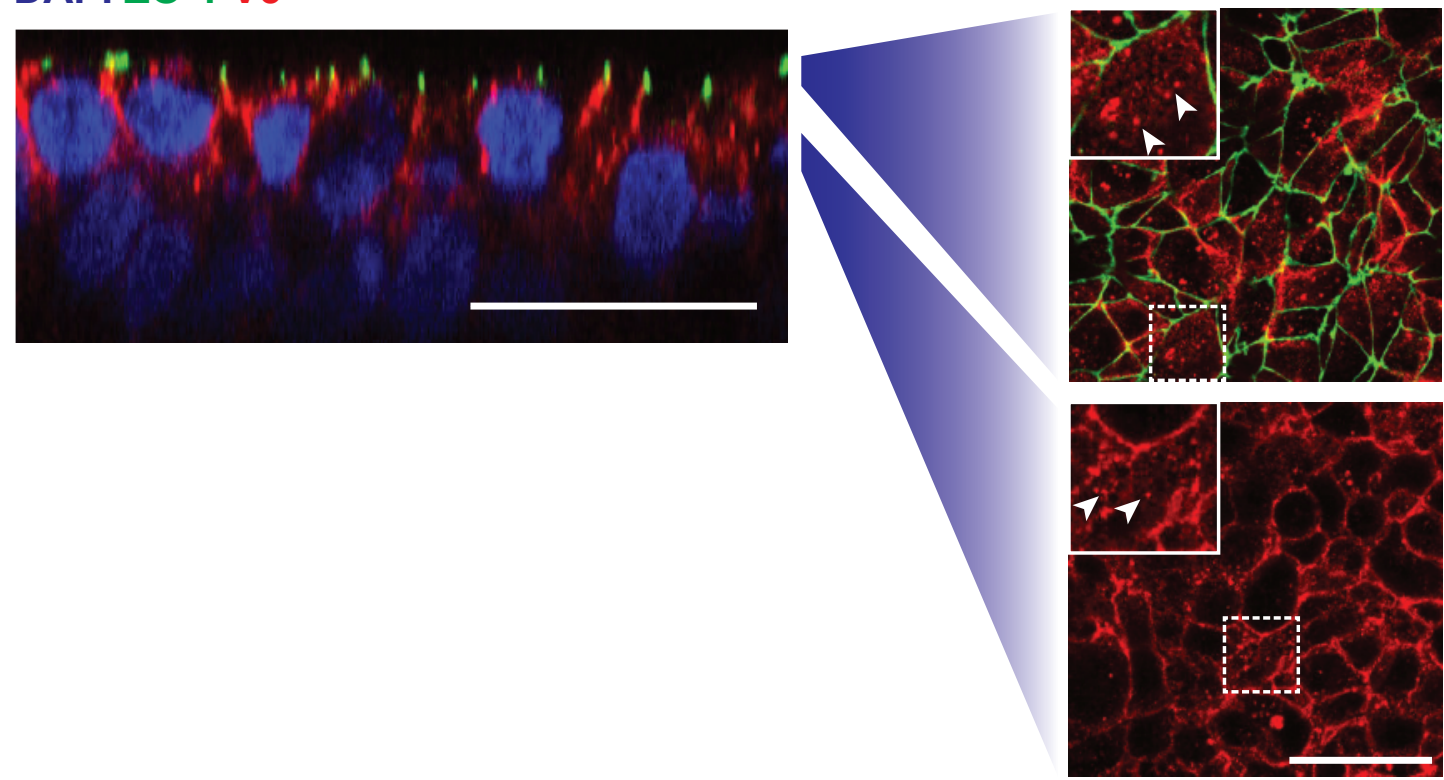


\section{F6}

biORxiv preprint doi: https://doi.org/10.1101/2020.12.18.423440; this version posted December 19, 2020. The copyright holder for this preprint (which was not certified by peer review) is the author/funder, who has granted bioRxiv a license to display the preprint in perpetuity. It is made

\begin{tabular}{c|ccccccc} 
& \multicolumn{7}{c}{$37^{\circ} \mathrm{C}$ available under aCE.BY-ND 4.0} \\
\cline { 2 - 7 } Basal BMP4 & + & + & + & + & + & + \\
\hline Apical NOGGIN & - & + & - & - & + & - \\
\hline Basal NOGGIN & - & - & + & - & - & +
\end{tabular}

PSMAD $1 / 5 / 8$

NOGGIN

Vinculin

B

\begin{tabular}{c|ccccc} 
Apical NOGGIN & - & + & - & + & - \\
\hline Basal NOGGIN & - & - & + & - & + \\
\hline Dyngo4a & - & - & - & + & + \\
NOGGIN & & & & & \\
Vinculin & & & & &
\end{tabular}

C

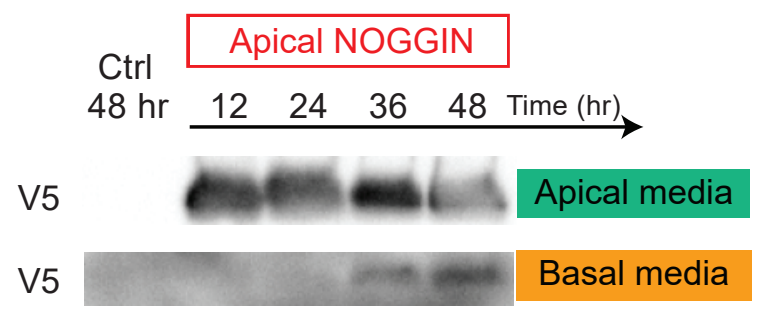

D

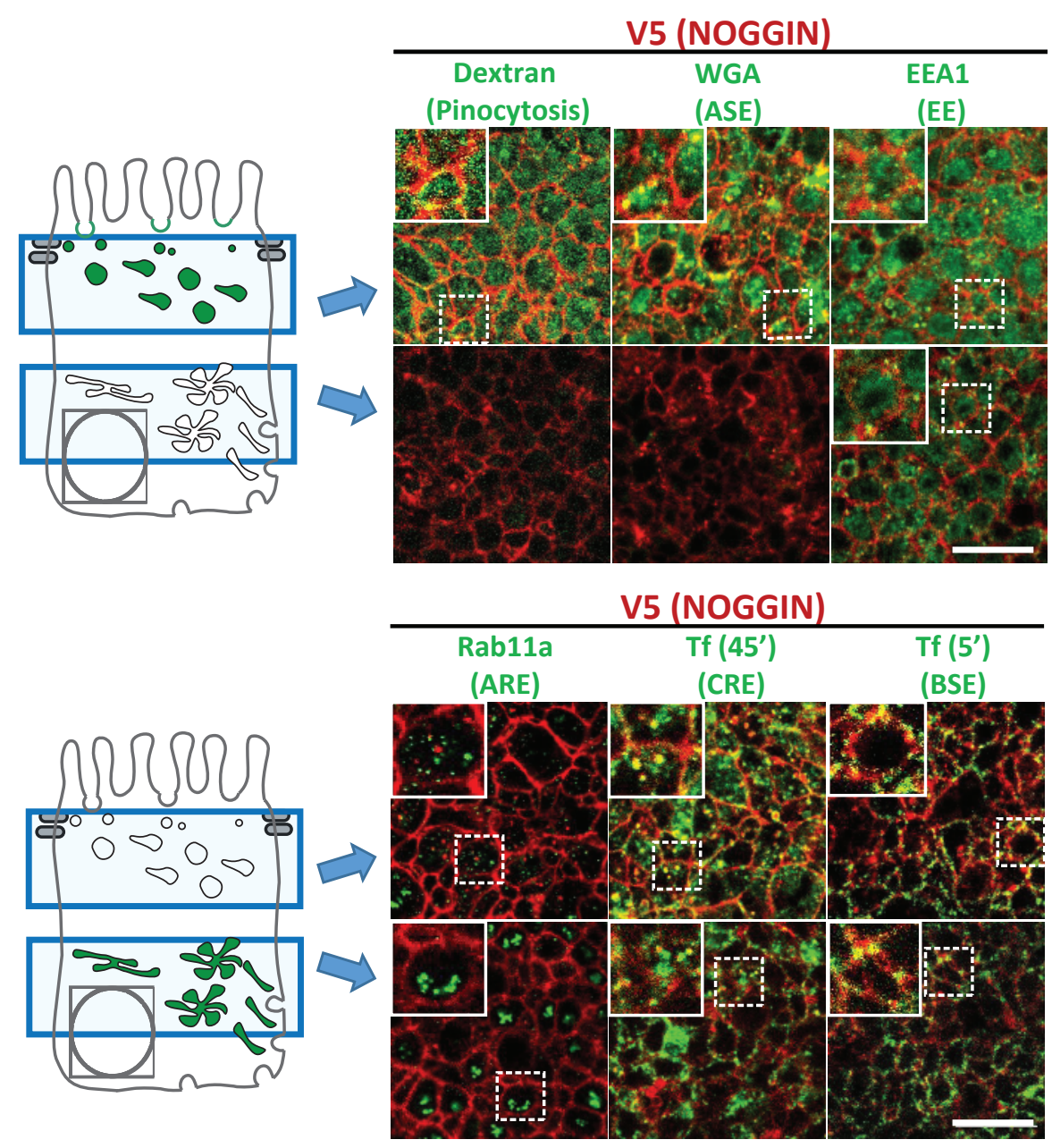


E bioRxiv preprint doi: https://doi.org/10.1101/2020.12.18.423440; this version posted December 19, 2020. The copyright holder for this preprint (which was not certified by peer review) is the author/funder, who has granted bioRxiv a license to display the preprint in perpetuity. It is made
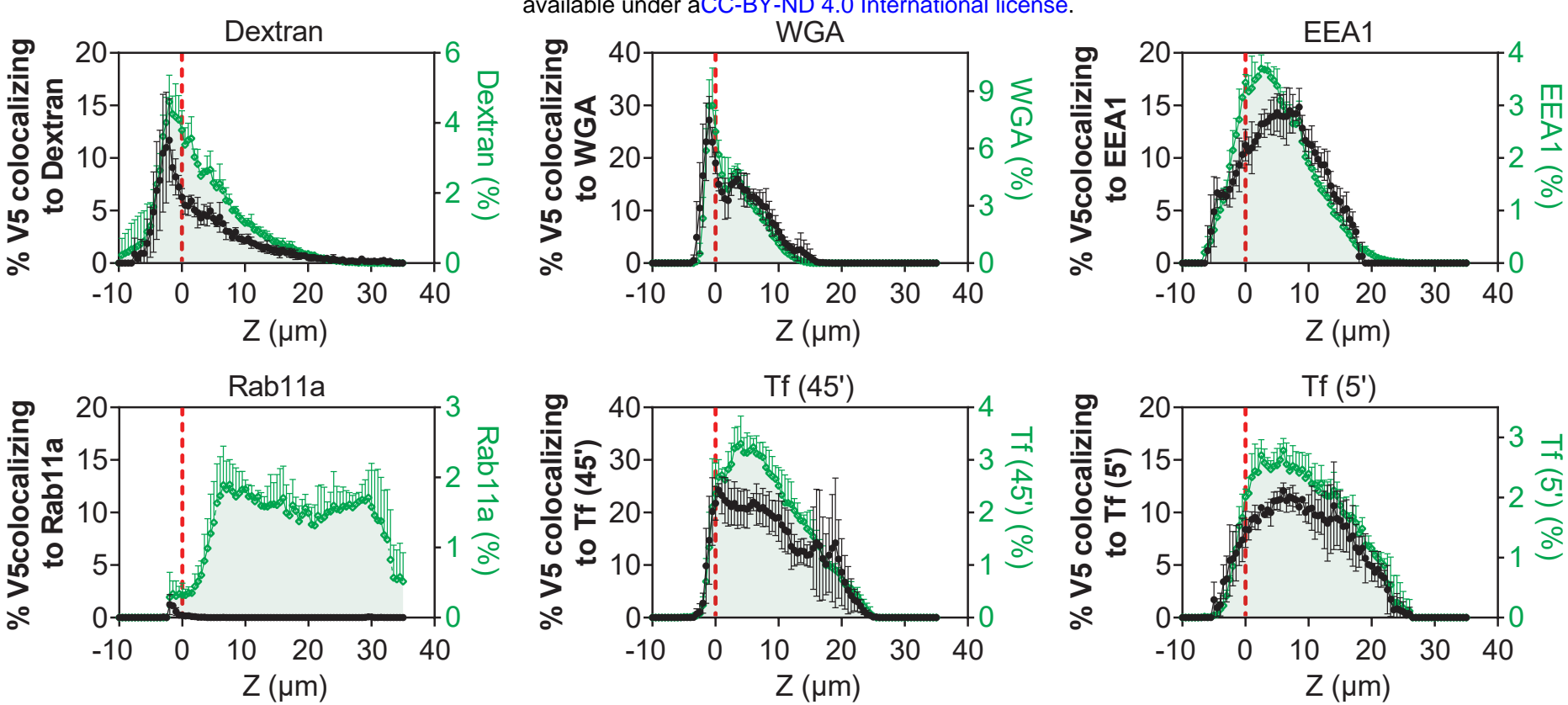
bioRxiv preprint doi: https://doi.org/10.1101/2020.12.18.423440; this version posted December 19, 2020. The copyright holder for this preprint

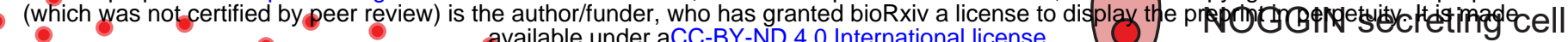

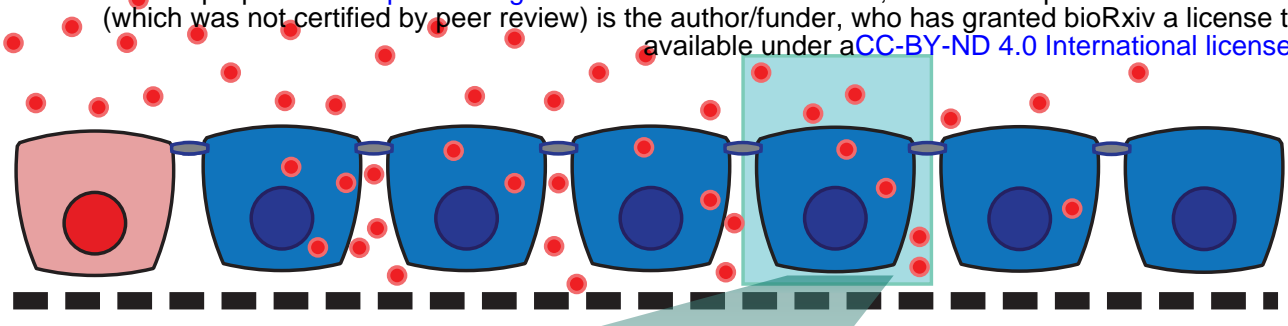

(1) NOGGIN receiving cell

- NOGGIN

$\longrightarrow$ Tight junction

- Filter
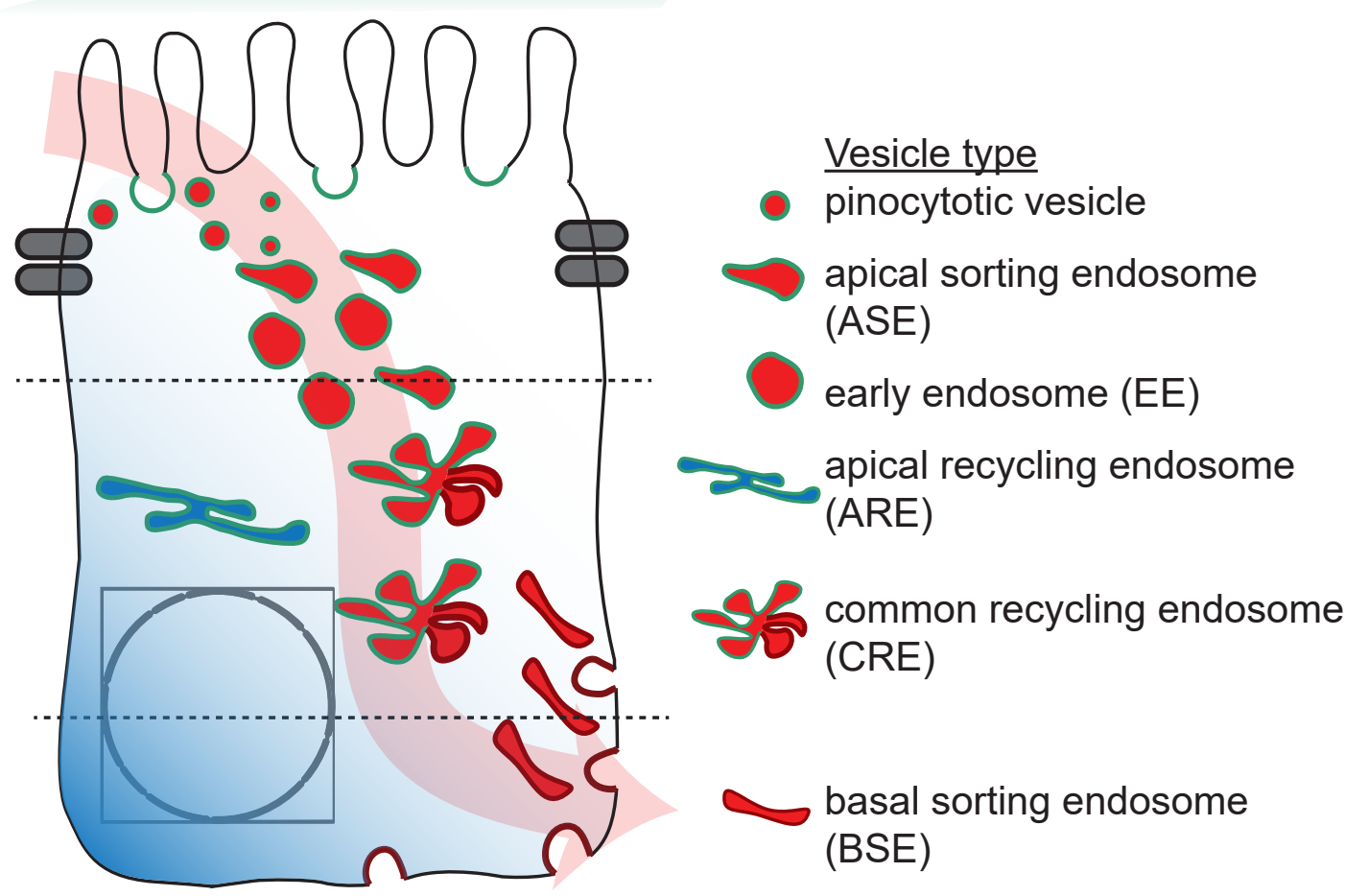

Marker

Dextran (10 kDA)

WGA (10')

EEA1

Rab11a

Tf (45')

$\operatorname{Tf}\left(5^{\prime}\right)$

(BSE) 